\section{Pacific Northwest}

National Laboratory

Operated by Battelle for the

U.S. Department of Energy

\title{
Evaluation of Exothermic Reactions from Bullk-Vitrification Melter Feeds Containing Cellulose
}

\author{
R. D. Scheele \\ B. K. McNamara \\ L. M. Bagaasen \\ S. J. Bos \\ A. E. Kozelisky \\ P. K. Berry
}

April 2007

Prepared for the U.S. Department of Energy under Contract DE-AC05-76RL01830 


\title{
DISCLAIMER
}

This report was prepared as an account of work sponsored by an agency of the United States Government. Neither the United States Government nor any agency thereof, nor Battelle Memorial Institute, nor any of their employees, makes any warranty, express or implied, or assumes any legal liability or responsibility for the accuracy, completeness, or usefulness of any information, apparatus, product, or process disclosed, or represents that its use would not infringe privately owned rights. Reference herein to any specific commercial product, process, or service by trade name, trademark, manufacturer, or otherwise does not necessarily constitute or imply its endorsement, recommendation, or favoring by the United States Government or any agency thereof, or Battelle Memorial Institute. The views and opinions of authors expressed herein do not necessarily state or reflect those of the United States Government or any agency thereof.

\author{
PACIFIC NORTHWEST NATIONAL LABORATORY \\ operated by \\ BATTELLE \\ for the \\ UNITED STATES DEPARTMENT OF ENERGY \\ under Contract DE-ACO5-76RL01830
}

Printed in the United States of America
Available to DOE and DOE contractors from the
Office of Scientific and Technical Information,
P.O. Box 62, Oak Ridge, TN 37831-0062;
ph: (865) 576-8401
fax: (865) 5765728
email: reports@adonis.osti.gov

\footnotetext{
Available to the public from the National Technical Information Service, U.S. Department of Commerce, 5285 Port Royal Rd., Springfield, VA 22161 ph: (800) 553-6847 fax: (703) 605-6900

email: orders@nits.fedworld.gov online ordering: http://www.ntis.gov/ordering.htm
} 


\title{
Evaluation of Exothermic Reactions from Bulk- Vitrification Melter Feeds Containing Cellulose
}

\author{
R. D. Scheele \\ B. K. McNamara \\ L. M. Bagaasen \\ S. J. Bos \\ P. K. Berry
}

April, 2007

Prepared for

the U.S. Department of Energy

under Contract DE-AC05-76RL01830

Pacific Northwest National Laboratory

Richland, Washington 99352 


\section{Summary}

The baseline bulk-vitrification (BV) process (also known as in-container vitrification ICV ${ }^{\mathrm{TM}}$ ) includes a mixer/dryer to convert liquid waste into a dried, blended feed for vitrification. Feed preparation includes blending liquid low-activity waste (LAW) with glass-forming minerals and cellulose and drying the mixture to a suitable dryness, consistency, and particle size for transport to the $\mathrm{ICV}^{\mathrm{TM}}$ container.

This drying process is conducted under vacuum in the temperature range of 60 to $80^{\circ} \mathrm{C}$. The nominal melting process starts with a refractory-lined metal box that is partially filled with feed. The refractory lining is referred to as the castable refractory block (CRB). Heat is applied in the form of electrical power through two graphite electrodes. Initially, the electrical current is carried through a graphite starter path, but as the feed is heated, it forms a molten glass that becomes the electrical conductor. The feed subsides as the glass is formed, allowing more feed to be added to the top of the melt in a feed-while-melt operation that continues until the box is filled to the desired level with glass.

A full-scale (FS) test (FS-38C) was conducted in CY06 (Witwer et al. 2007), which evaluated using a thick cold cap of feed to condense volatile contaminants and increase the single-pass retention of those contaminants in the BV melt. Using a thick cold cap resulted in high single-pass retentions and significant quantities of molten ionic salt (MIS) outside the CRB panels, which is thought to be related to the thick cold cap.

The main problem with MIS outside of the CRB panels is that radionuclides in the LAW are also initially salts and are concentrated in the MIS. If the MIS migrates to cooler regions of the ICV ${ }^{\text {TM}}$, the salts either do not decompose, or they partially decompose to form glasses with poor durability. This is undesirable as the unreacted salts and low-durability glasses are susceptible to leaching after disposal. The significant quantities of MIS in the FS-38C test are also thought to be related to the high concentration of lowmelting nitrates in the Tank 241-S-109 simulant (S-109) used for the test.

Because Tc is carried into the CRB by MIS, decreasing MIS migration into the CRB would proportionally decrease the concentration of the soluble Tc in the refractory lining. Current activities are exploring several methods for controlling MIS migration but focus mainly on methods to decrease the MIS mobility within the BV feed. These studies find that the MIS mobility is decreased by 1) increasing the specific surface area of solids and 2) adding organic carbon to denitrate the feed and reduce the amount of MIS. Using solids with fine grains or grinding the existing solids (soil) reduces migration by bonding free MIS to solid grains by capillary forces. Adding organic carbon decreases the amount of MIS in the feed by destroying its main components, nitrates and nitrites, at temperatures below $300^{\circ} \mathrm{C}$.

Because of cellulose's effectiveness as a denitrating agent for MIS, Hrma et al. (2005) further investigated cellulose addition based on Smith et al.'s (1999) postulated stoichiometry

$$
\mathrm{C}_{6} \mathrm{H}_{10} \mathrm{O}_{5}+6 \mathrm{NaNO}_{3} \rightarrow 3 \mathrm{Na}_{2} \mathrm{CO}_{3}+3 \mathrm{CO}_{2}+5 \mathrm{H}_{2} \mathrm{O}+2 \mathrm{~N}_{2}+\mathrm{N}_{2} \mathrm{O}+\mathrm{O}_{2}
$$

or at a 1:1 C:N molar ratio. Pacific Northwest National Laboratory's (PNNL's) laboratory experience (Hrma et al. 2007; Shimskey et al. 2007) has shown that cellulose added at concentrations supplying 0.75 moles of carbon for every mole of nitrogen in the feed effectively reduced the amount of MIS penetration and did not visibly react in 22-liter dryer tests during normal vacuum drying at $70^{\circ} \mathrm{C}$. 
However, because of potential increased reactivity at off-normal conditions, the project pursued the studies described in this report to assess how reactive cellulose-containing BV feeds are at various potential off-normal conditions during the operation of future BV facilities.

To assess the addition of cellulose as a denitrating and MIS-reducing agent for BV feed, we studied the reaction to determine the thermal-reaction sensitivity and heat- and gas-release potential during drying and melting of cellulose-loaded simulated Hanford LAW BV feed prepared for engineering-scale (ES) test ES-31F.

The ES-31F test is the last of a series of three ES tests (ES-30J, ES-30K, and ES-31F) that were designed to demonstrate potential solutions to reduce MIS migration. The ES-30J test established that an improved ES setup detected MIS migration in a melt that used a baseline feed formulation that contained course Hanford soil and no cellulose. The ES-30K test demonstrated that changing the Hanford soil to fine grained glass-forming minerals and adding cellulose to the formulation significantly reduced MIS penetration. The ES-31F test showed that the modified formulation, along with a controlled cold-cap approach, further reduced MIS penetration. The ES-31F feed was the focus of this investigation because it was representative of the feeds planned for future BV investigations.

This report provides the results of PNNL's scoping studies investigating the thermal denitration of alkaline Hanford LAW using cellulose. As we did in our earlier investigations on the reactivity of sucrose's reactions with nitrate/nitrite in simulated 6-tank composite waste (Kim et al. 2005), we used thermogravimetric analysis and differential thermal analysis. We also added 1) accelerating rate calorimetry to determine thermal sensitivity and provide another measure of reaction energies or enthalpies and 2) infrared spectrometry and mass spectroscopy to characterize the residual gases from the ARC experiments.

PNNL's thermoanalytical studies of cellulose's reaction with nitrate and nitrite in the ES-31F simulated BV feed found that

- the reaction proceeds in three distinct steps beginning at $100^{\circ} \mathrm{C}$ and ending at $550^{\circ} \mathrm{C}$

- the principal product gases are those postulated by Smith et al. (1999)

- only small amounts of the flammable gases hydrogen or methane are present in the residual gases

- for 1- to 6-g quantities, the reaction onset temperature for $\mathrm{ES}-31 \mathrm{~F}$ feed is near $100^{\circ} \mathrm{C}$ under adiabatic conditions, which is less than the $50^{\circ} \mathrm{C}$ rule-of-thumb safety margin recommended by the Center for Chemical Process Safety (CCPS) (Heemskerk et al. 1995) for reactive chemical systems with no engineered controls of the expected operational temperature of the dryer

- once initiated under adiabatic conditions, the cellulose nitrate reaction or series of reactions will continue until completed with significant gas release

- engineering analyses of actual process systems are required to determine if the reaction is capable of sustaining itself under non-adiabatic conditions. Although the DTA analyses suggest that when gases are rapidly exhausted from the chemical system, significant heat is removed, these DTA analyses are not representative of larger chemical systems where the product, heat-bearing gases have an opportunity to significantly interact with residual solids. Such evaluations would require an understanding of the chemical process, reaction rates, and thermal properties (e.g., thermal conductivity) under any particular set of process or process upset conditions. 
- additional studies are needed to unconfound the chemistry of the nitrate/cellulose chemical system to better understand whether a reaction is due to the decomposition of cellulose or the binary reaction between the nitrate and cellulose or whether the observed reaction arises from the reaction of nitrate with the cellulose decomposition products. Such information permits a knowledgeable development of mitigating or accommodating strategies.

In summary, our studies indicate that the cellulose-treated LAW is a complex chemical system capable of supporting self-propagating reactions that are observable by the $\mathrm{ARC}$ near $100^{\circ} \mathrm{C}$. It is worth noting that in other larger scale (22 L) drying operations, no exothermic reactions were observed. The chemical mechanism and the products, including the gaseous products, are not well characterized. Because the cellulose/nitrate reaction is capable of supporting self-sustaining reactions beginning within $50^{\circ} \mathrm{C}$ (the CCPS-recommended safety margin) of the vacuum dryer operating temperature of $60^{\circ} \mathrm{C}$, engineering evaluations are recommended to make sure that the engineered systems have the capability to mitigate heat and gas-production rates and that storage conditions and the time to prepare feed will preclude a propagating reaction. 



\section{Acronyms}

$\begin{array}{ll}\text { AIChE } & \text { American Institute of Chemical Engineers } \\ \text { ARC } & \text { accelerating rate calorimetry } \\ \text { BV } & \text { bulk vitrification } \\ \text { CCPS } & \text { Center for Chemical Process Safety } \\ \text { Cp } & \text { heat capacity at constant pressure } \\ \text { CRB } & \text { castable refractory block } \\ \text { CV } & \text { heat capacity at constant volume } \\ \Delta E & \text { internal energy change } \\ \Delta H & \text { enthalpy change } \\ \text { DSC } & \text { differential scanning calorimetry } \\ \text { DTA } & \text { differential thermal analysis } \\ \text { DTG } & \text { differential thermal gravimetric analysis } \\ \text { ES } & \text { engineering scale } \\ \text { FS } & \text { full scale } \\ \text { GFM } & \text { glass-forming mineral } \\ \text { ICVTM } & \text { in-container vitrification } \\ \text { IR } & \text { infra red } \\ \text { LAW } & \text { low-activity waste } \\ \text { MIS } & \text { molten ionic salt } \\ \text { MS } & \text { mass spectrometry } \\ \text { PNNL } & \text { Pacific Northwest National Laboratory } \\ \text { psia } & \text { pounds per square inch (relative to vacuum) } \\ \text { T } & \text { temperature } \\ \text { TG } & \text { thermogravimetric } \\ \text { TGA } & \text { thermogravimetric analysis } \\ & \end{array}$





\section{Contents}

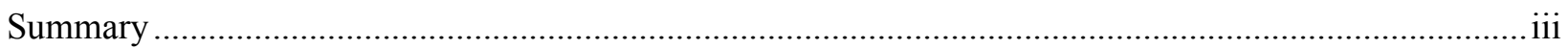

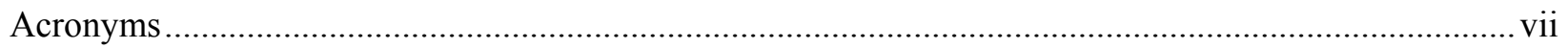

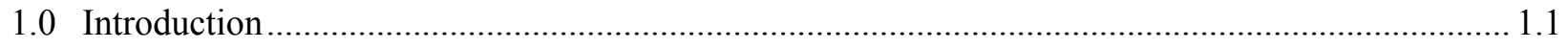

1.1 Considerations Concerning Reactivity of Organic/Waste Mixtures ...................................... 1.3

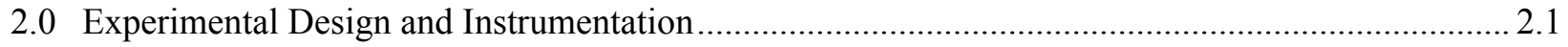

2.1 Simulated Bulk Vitrification Feed Used for Testing .......................................................... 2.1

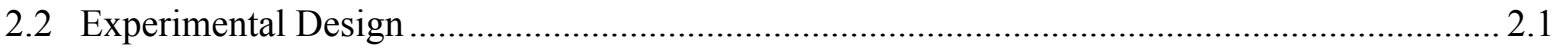

2.3 Thermogravimetric Analysis/Differential Thermal Analysis................................................. 2.2

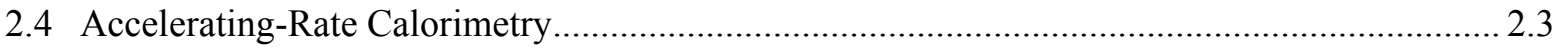

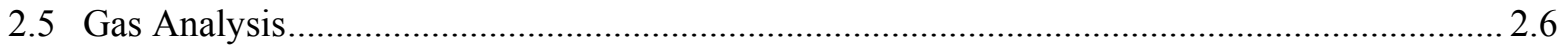

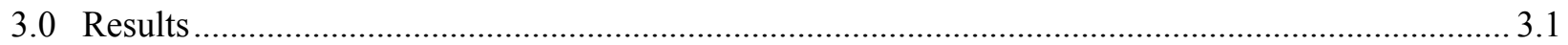

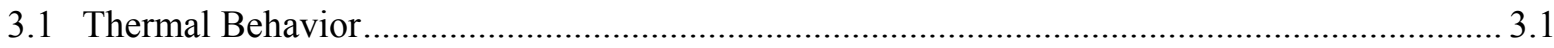

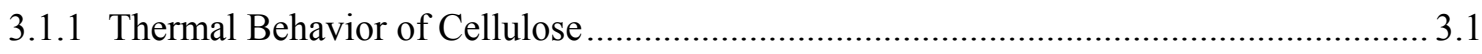

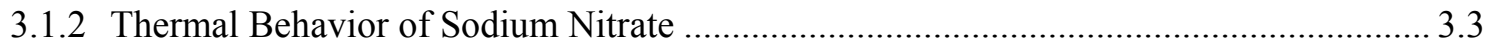

3.1.3 Thermal Behavior of Sodium Nitrate and Cellulose Mixtures ........................................ 3.4

3.1.4 Thermal Behavior of Simulated Waste as Measured by TGA/DTA …........................... 3.8

3.1.5 Thermal Sensitivity of Cellulose-Spiked ES-31F Feed as Measured by TGA/DTA....... 3.8

3.2 Thermal Behavior of ES-31F Simulated Feed as Measured by ARC .................................... 3.12

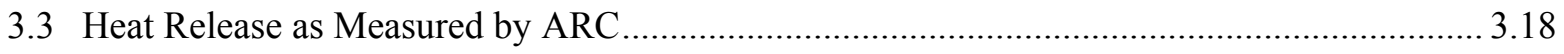

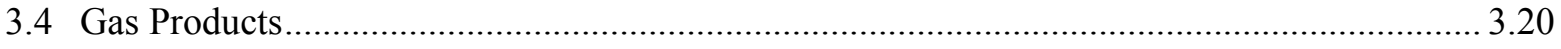

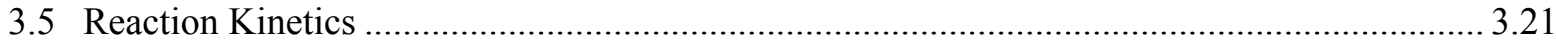

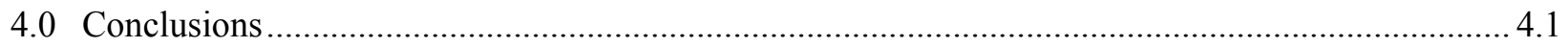

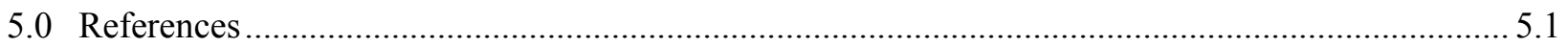




\section{Figures}

2.1. Schematic and Picture of a Columbia Scientific [Austin, TX] Accelerating Rate

Calorimeter

3.1. Thermal Behavior of 10-mg Cellulose as Measured by DTA and TGA

3.2. Arrhenius Plot of Thermal Behavior of $2.4 \mathrm{~g}$ Cellulose as Measured by ARC with a Titanium Sample Container.

3.3. Thermal Behavior of $2.1 \mathrm{~g}$ Sodium Nitrate as Measured by ARC in a Titanium Sample Container.

3.4. Thermal Behavior of a $1.2 \mathrm{~g}$ Mixture of Cellulose and Sodium Nitrate $(\mathrm{C}: \mathrm{N}=0.73)$ as Measured by ARC

3.5. Thermal Behavior of a $2.5 \mathrm{~g}$ Cellulose and Sodium Nitrate Mixture $(\mathrm{C}: \mathrm{N}=0.79)$ as Measured by ARC

3.6. Thermal Behavior of a Mixture of $1.2 \mathrm{~g}$ Cellulose and Sodium Nitrate $(\mathrm{C}: \mathrm{N}=13)$ as Measured by ARC

3.7. Thermal Behavior of Simulated S-109 Waste Used for Testing as Measured by TGA/DTA

3.8. Thermal Behavior of Simulant ES-31F Feed as Measured by TGA at Heating Rates of 2 to $20^{\circ} \mathrm{C} / \mathrm{min}$ (includes single DTG)

3.9. Thermal Behavior of ES-31F Feed as Measured by DTA at Heating Rates Ranging from 2 to $20^{\circ} \mathrm{C} / \mathrm{min}$

3.10. Thermal Behavior of $1 \mathrm{~g}$ ES-31F Simulated Feed as Measured by ARC, Analysis \#1...

3.11. Thermal Behavior of $1 \mathrm{~g}$ ES-31F Simulated Feed as a Function of Time as Measured by ARC, Experiment $\# 1$.

3.12. Thermal Behavior of $1 \mathrm{~g}$ Simulated ES-31F Feed as Measured by ARC, Experiment \#2

3.13. Thermal Behavior of 6-g ES-31F Feed Sample as Measured by ARC up to $225^{\circ} \mathrm{C}$

3.14. IR Spectrum of Residual Gases from Heating Simulated ES-31F Feed, ARC Experiment\#2 ...... 3.21

3.15. IR Spectrum of Residual Gases from Third ARC Analysis of ES-31F Simulated Feed

3.16. Plot of $\beta$ vs $1 / \mathrm{T}$ to Determine Arrhenius Kinetic Parameters (Kissinger 1957)..... 


\section{Tables}

1.1. AIChE Enthalpy Density Hazard Screening Guidelines............................................................... 1.3

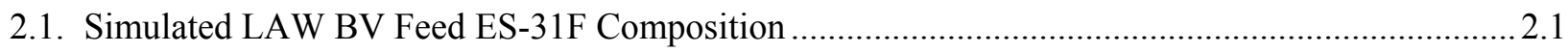

3.1. Cumulative Mass Loss from Thermal Cellulose Denitration of the ES-31F Feed .........................3.11

3.2. DTA-Measured Enthalpies of the Cellulose/Nitrate Reaction in ES-31 Feed Simulant.................. 3.12

3.3. Initial and Final Mass, Temperature, and Pressure Conditions for the ARC Trials .......................3.13

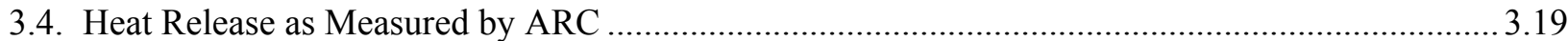

3.5. Residual Gases from Second ARC Experiment as Measured by MS ........................................... 3.20 


\subsection{Introduction}

The baseline bulk-vitrification (BV) process (also known as in-container vitrification ICVTM) includes a mixer/dryer to convert liquid low-activity waste (LAW) into a dried, blended feed for vitrification. Feed preparation includes blending LAW with glass-forming minerals (GFMs) and cellulose and drying the mixture to a suitable dryness, consistency, and particle size for transport to the $\mathrm{ICV}^{\mathrm{TM}}$ container.

This drying process is conducted under vacuum in the temperature range of 60 to $80^{\circ} \mathrm{C}$. The nominal melting process starts with a refractory-lined metal box that is partially filled with feed. The refractory lining is referred to as the castable refractory block (CRB). Heat is applied in the form of electrical power through two graphite electrodes. Initially, the electrical current is carried through a graphite starter path, but as the feed is heated, it forms a molten glass that becomes the electrical conductor. The feed subsides as the glass is formed, allowing more feed to be added to the top of the melt in a feed-while-melt operation that continues until the box is filled to the desired level with glass.

The full-scale (FS) test conducted in CY06 (FS-38C) (Witwer et al. 2007) evaluated using a thick cold cap of feed to condense volatile contaminants and increase the single-pass retentions of those contaminants in the BV melt. The use of a thick cold cap resulted in high single-pass retentions and significant quantities of molten ionic salt (MIS) outside the CRB panels, which is thought to be related to the use of a thick cold cap.

The main problem with MIS outside of the CRB panels is that radionuclides in the waste are also initially in the form of salts and are concentrated in the MIS. If the MIS migrates to cooler regions of the ICV ${ }^{\mathrm{TM}}$, the salts do not decompose, or they partially decompose to form glasses with poor durability. These salts and low-durability glasses are susceptible to leaching after disposal. The significant quantities of MIS in FS-38C are also thought to be related to the high concentration of low-melting nitrates in the Tank 241-S-109 simulant (S-109) used for the test.

Previous Pacific Northwest National Laboratory (PNNL) work (Hrma et al. 2005; Bagaasen et al. 2006; Kim et al. 2005) described how a substantial portion of the well dispersed and very minute radiocomponent technetium (Tc) can segregate from a large volume of feed and migrate into a porous refractory wall that is contacted by that feed. The BV melter feed used in the FS-38C test was a mixture of an LAW S-109 simulant, soil (Hanford soil), and additives $\left(\mathrm{ZrO}_{2}\right.$ and $\left.\mathrm{B}_{2} \mathrm{O}_{3}\right)$ that improve glass durability. The S-109 simulant is a mixture of salts, predominantly nitrates. As the feed-temperature increases, a single MIS phase that incorporates some $\mathrm{B}_{2} \mathrm{O}_{3}$ is formed from the LAW simulant salts. The MIS wets the grains of feed solids, spreading over and bridging them, and fills some of the space between the grains. The MIS begins to form at a temperature as low as $150^{\circ} \mathrm{C}$, is fully developed by $450^{\circ} \mathrm{C}$, and is nearly fully incorporated into the glass-forming phase by $800^{\circ} \mathrm{C}$. By $300^{\circ} \mathrm{C}$, the amount of MIS is sufficient to allow migration through the CRB. The CRB contains fine open pores that adsorb the free MIS and are capable, provided that an ample supply of MIS is available, of transferring the MIS through the refractory wall and depositing it on its outer surface. The low viscosity of molten salts, which is close to that of water, facilitates MIS penetration into the CRB.

Because Tc is carried to the CRB by MIS, decreasing the MIS migration into the CRB would proportionally decrease the concentration of the soluble Tc in the refractory lining. Current activities are exploring several methods for controlling MIS migration but focus mainly on methods to decrease the 
MIS mobility within the BV feed. These studies found that the MIS mobility was decreased by 1) increasing the specific surface area of solids and 2) adding organic carbon to denitrate the feed and reduce the amount of ionic salts. Using solids with fine grains or grinding the existing solids (soil) reduces migration by bonding free MIS to solid grains by capillary forces. Additions of organic carbon decrease the amount of MIS in the feed by destroying its main components, nitrates and nitrites, starting at temperatures below $300^{\circ} \mathrm{C}$.

Hrma and coworkers performed experiments to determine the type and quantity of carbon source that will not prematurely react during vacuum drying of the BV feed, but will destroy the nitrates before they have a chance to migrate at and above $300^{\circ} \mathrm{C}$. The carbon source also must not interfere with drying operations or transporting the dry feed from the dryer to the ICV TM box. Their studies included sucrose, starch, and cellulose.

A series of progressively larger drying and melting tests were conducted to determine the reactivity of the different candidate carbon sources. Unconfined crucible melting tests showed that the cellulose-nitrate reaction did not initiate until a portion of the crucible reached temperatures of over $200^{\circ} \mathrm{C}$ but always initiated well before $300^{\circ} \mathrm{C}$ where MIS migration becomes a concern. Drying tests conducted with cellulose additions in both 22-liter and 130-liter dryers showed no tendency for self sustaining exothermic reactions when dried under vacuum in the temperature range of 60 to $80^{\circ} \mathrm{C}$. The cellulose also improved dryer operations by extending the acceptable range of feed moisture contents. Cellulose proved to be the best carbon source since it improved dryer operations and was reactive enough to react with nitrates at temperatures below $300^{\circ} \mathrm{C}$.

Smith et al. (1999) postulated that cellulose reacts with nitrate via the reaction

$$
\mathrm{C}_{6} \mathrm{H}_{10} \mathrm{O}_{5}+6 \mathrm{NaNO}_{3} \rightarrow 3 \mathrm{Na}_{2} \mathrm{CO}_{3}+3 \mathrm{CO}_{2}+5 \mathrm{H}_{2} \mathrm{O}+2 \mathrm{~N}_{2}+\mathrm{N}_{2} \mathrm{O}+\mathrm{O}_{2}
$$

or at a 1:1 C:N molar ratio. Hrma et al.'s (2005; 2007) laboratory experience has shown that cellulose added at concentrations supplying 0.75 moles of carbon for every mole of nitrogen in the feed effectively reduced the amount of MIS penetration and did not react in 22-liter dryer tests at nominal drying conditions. However, because of potential increased reactivity at off-normal conditions (see Section 1.1), the project pursued the studies described in this report to assess how reactive cellulose-containing BV feeds are at various potential off-normal conditions during the operation of future BV facilities.

As was recognized for sucrose as an added organic carbon source (Kim et al. 2005), cellulose and nitrate and/or nitrite reactions have potential reactivity issues. Thus, in support of the consideration of cellulose as a denitrating and MIS-reducing agent for BV feed, we performed a study to determine the thermalreaction sensitivity and heat- and gas-release potential of cellulose-loaded simulated Hanford LAW BV feed ES-31F as it is dried and melted.

The ES-31F test is the last of a series of three engineering-scale (ES) tests (ES-30J, ES-30K, and ES-31F) that were designed to demonstrate potential solutions to reduce MIS migration. The ES-30J test established that an improved ES setup detected MIS migration in a melt that used a baseline feed formulation that contained coarse Hanford soil and no cellulose. The ES-30K test demonstrated that changing the Hanford soil to fine-grained GFMs and adding cellulose to the formulation significantly reduced MIS penetration. The ES-31F test showed that the modified formulation along with a controlled cold-cap approach further reduced MIS penetration. The ES-31F feed was the focus of this investigation because it was representative of the feeds planned for future BV investigations. 
This report provides the results of PNNL's scoping studies investigating the thermal denitration of alkaline Hanford LAW using cellulose and extends our earlier thermal-reactivity studies regarding sucrose reactivity (Kim et al. 2005). For these studies, we used thermogravimetric analysis (TGA), differential thermal analysis (DTA), and accelerating rate calorimetry (ARC) to determine thermal sensitivity and provide measures of reaction energies or enthalpies. We also used infrared (IR) spectrometry and mass spectroscopy (MS) to characterize the product gases. These techniques were used to determine:

- onset temperatures for exothermic reactions between cellulose and the feed

- denitration efficiency

- an estimate of heat release

- gas release amount and rate

- self-heat rate of the sample

- identity of the off-gases, in particular, whether hydrogen is generated in significant quantities.

\subsection{Considerations Concerning Reactivity of Organic/Waste Mixtures}

When considering any process that involves the exothermic reaction of a strong oxidant, such as nitrate or nitrite, with an organic reductant, such as denitration with sucrose, the process designer must consider the thermal-reactivity hazards of the process. Factors that can be considered are energy density $(\mathrm{J} / \mathrm{g})$, the reaction rates and mechanisms, the amount of gas produced, the thermal conductivity of the system, the heat-absorption capacity of the mixture constituents, and other interdependent chemical and physical parameters.

The American Institute of Chemical Engineers (AIChE) provides both general guidance and detailed strategies for assessing processes or chemical mixtures for potential chemical-reactivity hazards (Heemskerk et al. 1995, pp. 28-52). AIChE's screening guidelines in Table 1.1 provide an approach for assessing thermal hazards, principally based on energy density.

Table 1.1. AIChE Enthalpy Density Hazard Screening Guidelines (Heemskerk et al. 1995, pp. 28-52)

\begin{tabular}{||c|c|l||}
\hline Degree of Hazard & $\begin{array}{c}\text { Reaction or Decomposition } \\
\text { Enthalpy, kJ/g (kcal/g) }\end{array}$ & $\begin{array}{c}\text { Possible Qualitative Interpretations of } \\
\text { Classifications }\end{array}$ \\
\hline High & $>3(>0.7)$ & Violently Exothermic; detonation likely \\
\hline Medium & 1.2 to $3(0.3$ to 0.7$)$ & Exothermic, detonation possible, deflagration likely \\
\hline Low & 0.4 to $1.2(0.1$ to 0.3$)$ & Deflagration possible \\
\hline Very Low & $<0.4(<0.1)$ & Propagation unlikely \\
\hline
\end{tabular}

AIChE warns the user that chemicals in the Very Low and Low hazard categories still have the potential to react and raise temperatures to more than $600^{\circ} \mathrm{C}$, "which can result in significant and severe gas production and high pressures."

If the hazard screen identifies a potential hazard, AIChE suggests approaches including using thermoanalytical methods such as DTA, differential scanning calorimetry (DSC), thermal gravimetric 
(TG), and ARC to identify reaction onset temperatures, enthalpies, and other factors that control the reactivity. For additional discussion, please see our report on nitrate and nitrite reactions with organic complexants used at Hanford (Scheele et al. 1995). Other relevant reports include those of Beitel (1976a; $1976 b ; 1976 c ; 1977)$ and Scheele et al. (2005) that present our results on the reactivity of nitratecontaining decontamination agents and cotton (cellulose polymer) cloths.

Should the screen or further evaluations indicate that a substance or chemical system has the potential for propagating self-sustaining reactions or has a high energy density, the process is not necessarily deemed unsafe. The process operator can develop mitigating strategies, such as designing the system with adequate capacity to remove chemical heat or make sure that the temperature can be maintained where the reaction can be prevented from accelerating. 


\subsection{Experimental Design and Instrumentation}

In this scoping study to provide preliminary information on the thermal sensitivity, reaction energy, and/or enthalpy as well as to identify product gases resulting from the reduction of nitrate in LAW feed to $\mathrm{BV}$, we used a combination TGA/DTA, ARC, IR, and MS gas analysis to study the thermal behavior of the simulated LAW ES-31F BV feed. This section provides the make-up composition of the cellulosecontaining ES-31F BV feed used for testing and a description of the equipment and its capabilities and applications.

\subsection{Simulated Bulk Vitrification Feed Used for Testing}

For our studies to determine the thermal behavior and characteristics of the reaction between cellulose added to reduce molten salt content by reducing nitrate, we used the vacuum-dried, simulated LAW BV feed ES-31F, having the composition provided in Table 2.1. Shimskey et al. (2007) of PNNL added cellulose at a rate of 0.75 mole $\mathrm{C} /$ mole $\mathrm{N}$ (either nitrate or nitrite) to the simulated LAW ES-31F BV feed and vacuum dried it in a $22-\mathrm{L}$ dryer. At this cellulose addition rate, $75 \%$ of the nitrate and nitrite should be destroyed, leaving $25 \%$ of the original nitrate and nitrite in the feed to thermally decompose during vitrification.

Table 2.1. Simulated LAW BV Feed ES-31F Composition

\begin{tabular}{|c|c|c|c|}
\hline Materials & Mass Fraction & Materials & Mass Fraction \\
\hline Kyanite & 0.092 & $\mathrm{Fe}_{2} \mathrm{O}_{3}$ (Waste) & 0.0002 \\
\hline $\mathrm{B}_{2} \mathrm{O}_{3}$ & 0.037 & $\mathrm{KNO}_{3}$ & 0.0004 \\
\hline Wollastonite & 0.042 & $\mathrm{NaNO}_{2}$ & 0.004 \\
\hline Olivine & 0.019 & $\mathrm{NaNO}_{3}$ & 0.2969 \\
\hline Sand & 0.278 & $\mathrm{NaOH}$ & 0.007 \\
\hline $\mathrm{ZrSiO}_{4}$ & 0.076 & $\mathrm{Na}_{3} \mathrm{PO}_{4} \cdot 12 \mathrm{H}_{2} \mathrm{O}$ & 0.018 \\
\hline Hematite (Glass Former) & 0.027 & $\mathrm{Na}_{2} \mathrm{SO}_{4}$ & 0.004 \\
\hline Rutile & 0.003 & $\mathrm{Na}_{2} \mathrm{CO}_{3} \cdot \mathrm{H}_{2} \mathrm{O}$ & 0.018 \\
\hline $\mathrm{Al}(\mathrm{OH})_{3}$ & 0.002 & $\mathrm{NaCH}_{3} \mathrm{COO}$ & 0.0005 \\
\hline $\mathrm{Ca}(\mathrm{OH})_{2}$ & 0.00004 & $\mathrm{Na}_{2} \mathrm{C}_{2} \mathrm{O}_{4}$ & 0.0006 \\
\hline $\mathrm{NaCl}$ & 0.0005 & $\mathrm{Re}_{2} \mathrm{O}_{7}$ & $8 \times 10^{-06}$ \\
\hline $\mathrm{Na}_{2} \mathrm{CrO}_{4}$ & 0.0004 & $\mathrm{CsNO}_{3}$ & $7 \times 10^{-06}$ \\
\hline $\mathrm{Na}_{2} \mathrm{CrO}_{4} \cdot 4 \mathrm{H}_{2} \mathrm{O}$ & 0.001 & $\mathrm{KI}$ & $6 \times 10^{-05}$ \\
\hline $\mathrm{Cr}_{2} \mathrm{O}_{3}$ & 0.0003 & $\mathrm{Na}_{2} \mathrm{HAsO}_{4} \cdot 7 \mathrm{H}_{2} \mathrm{O}$ & $4 \times 10^{-05}$ \\
\hline $\mathrm{NaF}$ & 0.00009 & Cellulose & 0.072 \\
\hline
\end{tabular}

\subsection{Experimental Design}

For this study, we investigated the thermal behavior of the simulated melter feed prepared for test ES-31F. The simulated feed is a mixture of simulated S-109 LAW mixed with cellulose (added on a 0.75:1 carbon to nitrate/nitrite nitrogen basis) and GFMs. The nominal stoichiometry identified by Smith et al. (1999) determined the nominal molar stoichiometry for the nitrate-reduction reaction to be 1:1; therefore, the simulated feed is designed to eliminate $75 \%$ of the nitrate and nitrite. 
We used the TGA/DTA to provide mass changes and a first estimate of the reaction enthalpies for the various denitration reactions and as a screening tool to determine the nominal thermal sensitivities of the reaction stages. TGA/DTA provides a reaction onset nominally within $100^{\circ} \mathrm{C}$ of the reaction onset temperature (Center for Chemical Process Safety [Heemskerk et al. 1995]). We also used the TGA/DTA to provide Arrhenius reaction parameters activation energy $\left(\mathrm{E}_{\mathrm{a}}\right)$ and preexponential or frequency factor $\mathrm{A}$.

We used the ARC to provide a more accurate measure of the reaction-onset temperature, reaction energy or enthalpy, and reaction kinetic parameters. Because of the ARC's increased sensitivity, the Center for Process Safety (CCPS) (Heemskerk et al. 1995) provides the rule-of-thumb criterion that processes operated at temperatures more than $50^{\circ} \mathrm{C}$ below the $\mathrm{ARC}$-observed reaction temperature should pose no thermal-reactivity hazard. We used 1-g samples to measure the thermal reactivity over the full reaction range up to $450^{\circ} \mathrm{C}$ and a full sample container $(6 \mathrm{~g})$ to improve the sensitivity of our measurement of the initial reaction onset temperature.

\subsection{Thermogravimetric Analysis/Differential Thermal Analysis}

For our TGA/DTA studies, we used a Model 320Seiko TGA and DTA instrument that measures mass changes (TGA) and temperature changes (DTA) of a 1- to 100-mg sample as the sample contained in an open platinum, gold, or aluminum pan is heated at a known and controlled heating ramp (e.g., $5^{\circ} \mathrm{C} / \mathrm{min}$ ) in a controlled atmosphere. We select the sample pan based on the chemical compatibility of the sample with the pan material. For these tests, we heated nominal $20-\mathrm{mg}$ samples to $550^{\circ} \mathrm{C}$ at heating rates ranging from 1 to $20^{\circ} \mathrm{C} / \mathrm{min}$ with $5^{\circ} \mathrm{C} / \mathrm{min}$ as the standard operating mode. We used flowing argon at $150 \mathrm{~mL} / \mathrm{min}$ to focus the instrument on the reaction between cellulose and nitrate-nitrite and eliminate any confounding reactions, such as that between oxygen in air with the cellulose. The various heating rates provide a mechanism to measure the Arrhenius kinetic parameters (Kissinger 1957).

This report presents the results of the TG analyses as both the mass change and the mass-change rate (differential thermal gravimetric analysis [DTG]). If a mass change occurs simultaneously with a reaction that produces or requires heat, the DTG provides directly comparable information to that of the DTA, thus allowing an easier correlation between types of reactions.

The DTA provides information on whether the reaction is heat-producing (exothermic) or requires heat (endothermic). The DTA can also be used for quantifying the heat required for an endothermic reaction or the exothermic heat produced. The latter is complicated for gas-producing reactions because the portion of the reaction heat contained within the gaseous products is swept away by the flowing gas and not seen by the instrument.

The instrument was routinely calibrated to assure the accuracy of the temperature, the enthalpy, and the mass measurements. The temperature and heat-measurement response was calibrated with melting-point and enthalpy standards for indium, lead, and tin metals. The accuracy and precision of the analytical balance in the instrument was checked with standard weights. These procedures were performed before and after a batch set of thermal analyses was completed.

We used two approaches with DTA results to calculate the Arrhenius reaction kinetic parameters for activation energy $E_{a}$ and pre-exponential or frequency factor A. We used 1) Kissinger's (1957) method and 2) the similar Ozawa (1965) and Flynn and Wall (1966) methods, each of which uses varying heating rates $\beta$ and the reaction peak's maxima. 
Kissinger's method uses the relationship:

$$
\operatorname{Ln}\left[\beta / T_{p}^{2}\right]=\operatorname{Ln}\left[\frac{A^{*} R}{E_{a}}\right]-\frac{E_{a}}{R * T_{p}}
$$

to calculate $E_{a}$ and $A$ from the DTA results. $\beta$ is the constant heating rate, $T_{p}$ is the peak maxima temperature in $\mathrm{K}$, and $\mathrm{R}$ is the gas constant. The activation energy $-\mathrm{E}_{\mathrm{a}}$ may be determined from the slope of a plot of $\ln \left(\beta / \mathrm{T}_{\mathrm{p}}{ }^{2}\right)$ versus $1 / \mathrm{T}_{\mathrm{p}}$.

Ozawa (1965) and Flynn and Wall (1966) use the relationship:

$$
\operatorname{Ln}[\beta]=-\frac{1.05 * E_{a}}{R^{*} T_{p}}+\operatorname{Ln}\left[\frac{A^{*} E_{a}}{R}\right]-C
$$

to determine $\mathrm{E}_{\mathrm{a}}$ and $\mathrm{A}$ from the DTA results. Again, $\mathrm{E}_{\mathrm{a}}$ can be determined from the slope of the straight line arising from the plot of $\ln \beta$ versus $1 /\left(60 \mathrm{~T}_{\mathrm{p}}\right)$ obtained from DTA measurements at the different heating rates $\beta$.

\subsection{Accelerating-Rate Calorimetry}

The ARC is an adiabatic calorimeter originally developed by Dow Chemical to determine safe process operating temperatures for tested materials. The ARC measures the rate of temperature and/or pressure increase that occurs for the tested materials maintained at adiabatic conditions, typically using the heatwait-search mode. In the ARC's heat-wait-search mode, the ARC heats the sample to an operatorprogrammed temperature, waits for an operator-selected time to equilibrate, and monitors the system's self-heat rate using an operator-selected criterion (e.g., $0.01{ }^{\circ} \mathrm{C} / \mathrm{min}$ for this testing) to determine if an exothermic reaction is occurring based on comparison to this operator-selected criterion. The ARC can heat a sample to an upper temperature of $450{ }^{\circ} \mathrm{C}$, and we used an upper internal sample pressure limit of 2000 psia.

In contrast to many of the other calorimetric methods such as DTA/TGA or the Reactive System Screening Tool, the ARC imposes no particular heating profile on the sample (a controlled heating rate) other than when a reaction is not observed. Rather, the ARC maintains the calorimeter based on the sample's and its container's thermal profile.

As shown in Figure 2.1, the ARC is simply a sample container (bomb) surrounded by a calorimeter ( 1 and 5) having multiple-zone heating elements. The heating is controlled by type $\mathrm{N}$ thermocouples distributed to assure uniform temperature throughout the calorimetric chamber. The combined sample and bomb temperature is measured at the $10-\mathrm{mL}$ bomb's equator (3). The oven's temperature is maintained at the same temperature as the sample and bomb to provide an adiabatic (no heat loss from the sample) environment for the sample. The ARC uses a pressure transducer (2) to measure pressure. The volume above the bomb to the pressure transducer is about $5 \mathrm{~mL}$. The $\mathrm{ARC}$ can heat to $450^{\circ} \mathrm{C}$ and can maintain adiabatic conditions up to heating rates no more than $15^{\circ} \mathrm{C} / \mathrm{min}$; i.e., the calorimeter cannot follow sample heating rates greater than $15^{\circ} \mathrm{C} / \mathrm{min}$. 

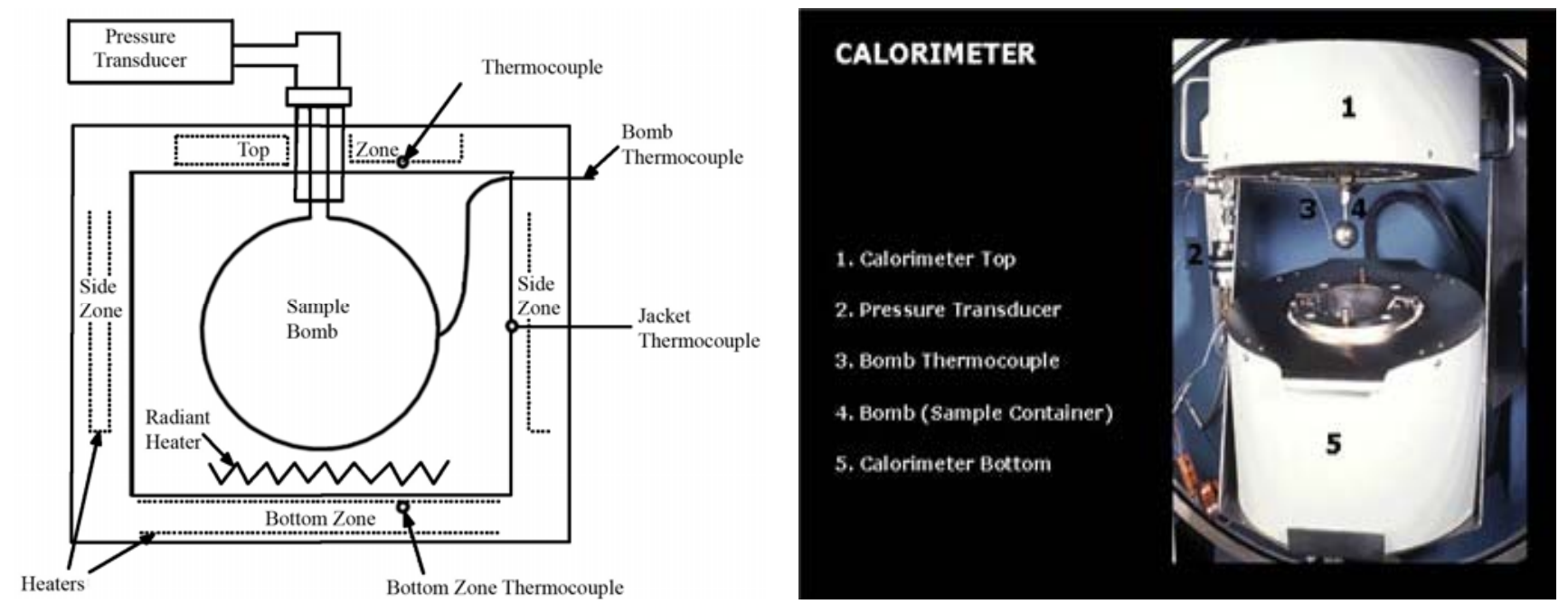

Figure 2.1. Schematic and Picture of a Columbia Scientific [Austin, TX] Accelerating Rate Calorimeter

Because the reactive system is adiabatically enclosed, measured rates of temperature and/or pressure are conservative with respect to purged or evacuated testing. The rule-of-thumb for assessing a thermalreactivity hazard based on the $\mathrm{ARC}$ results is that the maximum process temperature must be greater than $50^{\circ} \mathrm{C}$ below the ARC-observed reaction onset temperature (Heemskerk et al. 1995, pp. 28-52) without further evaluating the thermal character of the system; e.g., its ability to dissipate chemical heat.

The ARC maintains the oven temperature at the combined sample and container's temperature. The nominal thermal mass of the titanium bomb, $6.2 \mathrm{~g} \times 0.524 \mathrm{~J}^{*} \mathrm{~g}^{-1} *{ }^{\circ} \mathrm{C}^{-1}$ or $\sim 3.2 \mathrm{~J}^{* \circ} \mathrm{C}^{-1}$, causes the observed heating rate to be slower than the sample would be by itself. This thermal inertia is accounted for by multiplying the measured self-heat rate by the so-called $\Phi$-factor calculated by

$$
\Phi=1+\frac{\left(C_{p(\text { container })} \times \text { Mass }_{\text {container }}\right)}{\left(C_{p(\text { sample })} \times \text { Mass }_{\text {sample }}\right)}
$$

where $\mathrm{C}_{\mathrm{p} \text { (container) }}$ is the heat capacity of the titanium container, and $\mathrm{C}_{\mathrm{p} \text { (sample) }}$ is the heat capacity of the sample.

For constant-pressure processes, the heat of reaction $\Delta \mathrm{H}$ is calculated using the temperature rise and the heat capacity of the reactants, the products, and the sample container with the simple formula provided by ARC's instrument manual

$$
\Delta H=C_{p} * \Phi * \Delta T_{a b}
$$

where $C_{p}$ is the heat capacity of the sample and products at constant pressure, and $\Delta T_{a b}$ is the temperature change caused by the reaction. The application of this formula is complicated by many factors. For example, the ARC is a constant-volume device, and the heat capacity depends on the reaction composition and temperature, both of which are constantly changing during the ARC experiment. In our graphical presentations of ARC-measured thermal behavior, we use the convention of presenting a $\Phi$ factor adjusted self-heating rate $(\Phi \times$ self-heat rate) to capture the effect of the system's thermal inertia. 
For constant-volume processes, the system's internal energy change $(\Delta \mathrm{E})$ resulting from the reaction is calculated using

$$
\Delta E=C_{v} \times \Phi \times \Delta T
$$

where $\mathrm{C}_{\mathrm{v}}$ is the heat capacity at constant volume. The differences between $\mathrm{C}_{\mathrm{v}}$ and $\mathrm{C}_{\mathrm{p}}$ for solids and liquids are typically small because of their lack of compressibility. There can be significant differences for gases because of their compressibility, although $\Delta(\mathrm{PV})$ will be small with respect to enthalpy change $(\Delta \mathrm{H})$ or $\Delta \mathrm{E}(\Delta \mathrm{H}=\Delta \mathrm{E}+\Delta \mathrm{PV})$ where $\mathrm{P}$ is pressure and $\mathrm{V}$ is volume (Shoemaker et al. 1996). With respect to calculations of $\Delta \mathrm{H}$ using the ARC temperature rise, the primary thermal mass is from the sample container, which has limited compressibility permitting the use of $\mathrm{C}_{\mathrm{p}}$ rather than its $\mathrm{C}_{\mathrm{v}}$. Thus, for this report, we will use the operator manual-recommended use of $\mathrm{C}_{\mathrm{p}}$ rather than $\mathrm{C}_{\mathrm{v}}$. Raemy and Ottawy (1991) in their ARC studies use average $C_{p}$ for cellulose for the temperature range observed for the thermal exothermic decomposition of powder cellulose, providing additional justification for our decision.

The calculation of $\Delta \mathrm{H}$ is complicated by the unknown composition of the final reactant and product mixture, which affects the $\mathrm{C}_{\mathrm{p}}$ used for both the $\Delta \mathrm{H}$ and $\Phi$ calculations and the unknown amount of sodium nitrate present at its melting temperature; heat is required to melt the sodium nitrate, and this reaction will reduce the ARC-measured $\Delta \mathrm{H}$. We used the $\Phi$ for the room temperature reactant mixture to normalize the self-heat rates for the thermal mass of the container.

Because of these complexities, a more fundamental approach to calculate $\Delta \mathrm{H}$ was used than that recommended by the ARC operations manual. To calculate the reaction enthalpy, enthalpy's existence was used as a state function where the final state does not depend on the path. We thus assumed that the reaction proceeded to completion following Smith et al.'s (1999) stoichiometry at the ARC-observed onset temperature with no temperature increase. After reaction completion, we increased the temperature of each individual product to the final ARC temperature $\left(450^{\circ} \mathrm{C}\right)$. Thus, we calculated the reaction enthalpy by summing the enthalpy required to heat each individual product component from the initial temperature (T1) to the final temperature (T2), adding the enthalpy required to heat the sample container to $\mathrm{T} 2$, and finally, we added in the enthalpies for phase changes. The process is summarized per Equation 3.1 .

$$
\Delta H_{r x n}=\left[\sum_{i}\left(C_{p(s)[i]} \times m_{s[i]}\right) \times \Delta T\right]+\left[\left(C_{p(b)} \times m_{b}\right) \times \Delta T\right]+\Delta H_{P C}
$$

$\mathrm{C}_{\mathrm{p}(\mathrm{s})[\mathrm{i}]}, \mathrm{m}_{\mathrm{s}[\mathrm{i}]}, \mathrm{C}_{\mathrm{p}(\mathrm{b})}$, and $\mathrm{m}_{\mathrm{b}}$ are the temperature-averaged heat capacities at $\mathrm{T} 1$ (observed reaction onset temperature) and $\mathrm{T} 2$ (final observed reaction temperature) and masses of sample component $i$ and sample container, respectively, and $\Delta \mathrm{H}_{\mathrm{PC}}$ is the enthalpy change due to a phase change, such as the melting of $\mathrm{NaNO}_{3}$ (pure $\mathrm{NaNO}_{3} \mathrm{mp}=307^{\circ} \mathrm{C}$ ). Because the reaction had not ended when we terminated the ARC experiment, the ARC-measured $\Delta \mathrm{H}$ should be less than actual. We used Barin's (1989) heat capacities for the reaction products and the residual inerts.

The ARC can also provide Arrhenius kinetic parameters, either by using the early self-heat rate when the reaction is essentially zero order and/or by using Townsend and Tou's (1980) modeling of the thermal behavior. For this scoping study, we did not extract kinetic parameters from the ARC analysis. 


\subsection{Gas Analysis}

After the ARC experiment was finished, the off gases were collected at room temperature for analysis by infrared spectroscopy on a Nicolet 750 infrared spectrophotometer using a gas cell fitted with $\mathrm{NaCl}$ windows. The instrument was run at a resolution of $2 \mathrm{~cm}^{-1}$, and 32 spectra were collected for each gas sample.

Two gas samples were collected for gas analysis by mass spectroscopy in a calibrated volumetric cylinder from the ARC sample bomb. The volume of the collection cylinder was $24.6 \mathrm{~cm}^{3}$. The mass spectrometer was a high sensitivity, quantitative Finnigan Mat-271. The sensitivity of the instrument was routinely checked with high-purity nitrogen gas and high-purity air samples. 


\subsection{Results}

This section discusses the thermal behavior, measured reaction enthalpy, and measured residual gas composition after an ARC analysis of the ES-31F BV feed. We discuss the results as obtained by each of the thermoanalytical tools used.

\subsection{Thermal Behavior}

To characterize and understand the thermal behavior of the ES-31F BV feed, we used TGA/DTA and ARC to study the thermal behavior of cellulose, nitrate, and the feed itself. Each of these thermoanalytical methods provides direct information on the thermal-reaction sensitivity for a chemical system and can provide information on the reaction's $\Delta \mathrm{H}$ and reaction kinetics. This section provides our DTA/TGA- and ARC-measured thermal sensitivities, reaction enthalpies, and DTA-determined kinetic parameters.

\subsubsection{Thermal Behavior of Cellulose}

As the agent to eliminate MIS from the molten feed, cellulose's thermal behavior is important. Cellulose pyrolysis has been extensively studied by many laboratories using DTA, DSC, high-pressure DTA, TGA, heat flow (Calvet) calorimetry, and ARC (Raemy and Schweizer 1983; Raemy and Ottaway 1991; Várhegyi et al. 1993; Davies et al. 1983; Dollimore and Hoath 1981). As summarized by Raemy and Schweizer (1983), retention of volatiles released at low temperatures is critical for observing cellulose's nominal $200^{\circ} \mathrm{C}$ exothermic decomposition.

A variety of thermal behaviors for cellulose have been observed, depending on the experimental conditions used. In studies where the carbohydrate decomposition vapors are removed, no exothermic behavior is observed, but when the vapors are retained, exothermic behavior is observed. In their studies using heat flow calorimetry, Raemy and Schweizer (1983) found that cellulose decomposes exothermically at $220^{\circ} \mathrm{C}$, producing $-650 \mathrm{~J} / \mathrm{g}$ cellulose, and they also report that others found no exothermic behavior when decomposition vapors are removed. Raemy and Ottaway (1991) discovered using ARC that powdered cellulose decomposes exothermically at $180^{\circ} \mathrm{C}$ (onset detection self-heat rate criterion of $0.02^{\circ} \mathrm{C} / \mathrm{min}$ ) producing between -500 and $-650 \mathrm{~J} / \mathrm{g}$ cellulose. Scheele et al.'s (2005) ARC studies found similar exothermic behavior for cotton cellulose.

Using TG, Wu and Zavarin (1984) found that microcrystalline cellulose decomposes near $300^{\circ} \mathrm{C}$ when heated at $10^{\circ} \mathrm{C} / \mathrm{min}$. They presented DSC results up to $300^{\circ} \mathrm{C}$, which provide little indication of exothermic or endothermic decomposition. Scheele et al.'s (2005) TGA/DTA studies found that cotton cellulose in an $86 \%$ cotton $/ 14 \%$ polyester cloth decomposes endothermically at $300^{\circ} \mathrm{C}$ in flowing argon, although a very rapid small mass loss occurs at $180^{\circ} \mathrm{C}$.

It was found in DTA/TGA studies using aluminum pans, a heating rate of $5^{\circ} \mathrm{C} / \mathrm{min}$, and an argon purge that cellulose loses about 3 mass \% endothermically between room temperature and $100^{\circ} \mathrm{C}$ as shown in Figure 3.1. This is consistent with other studies where the decomposition gases were removed. This loss is likely desorption of absorbed water. At about $220^{\circ} \mathrm{C}$, the cellulose endothermically decomposes, losing another 80 mass $\%$ by $575^{\circ} \mathrm{C}$ where the experiment was terminated. 


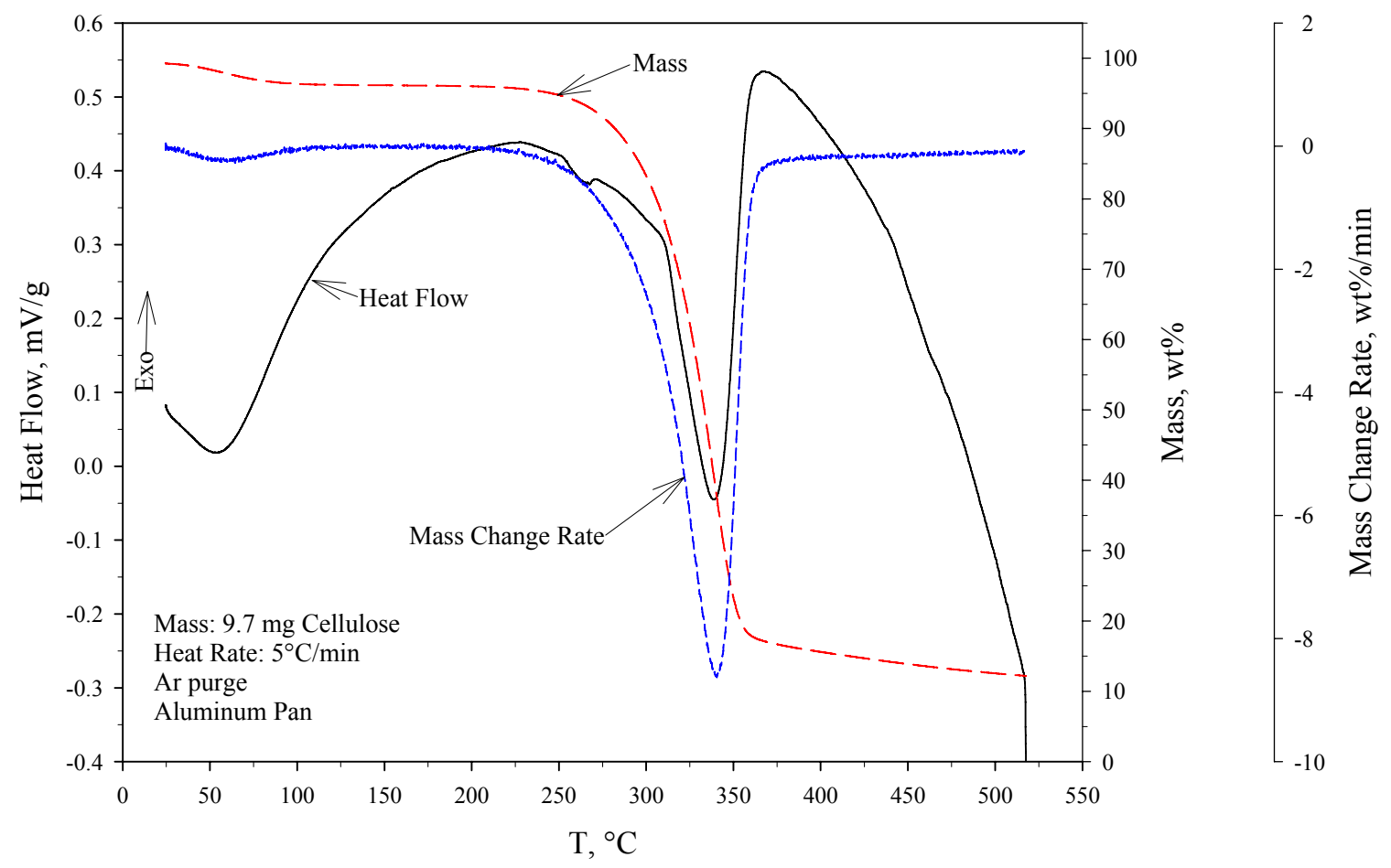

Figure 3.1. Thermal Behavior of 10-mg Cellulose as Measured by DTA and TGA

Similar to the exothermic decomposition of cotton cellulose (Scheele et al. 2005), Figure 3.2 shows that in the ARC, pure cellulose decomposes exothermically beginning near $200^{\circ} \mathrm{C}$ and ending near $280^{\circ} \mathrm{C}$ using an onset detection of $0.1{ }^{\circ} \mathrm{C} / \mathrm{min}$. With this onset criterion, the reaction enthalpy is $-280 \mathrm{~J} / \mathrm{g}$ cellulose, which is at least $40 \%$ less than the -500 to $-650 \mathrm{~J} / \mathrm{g}$ cellulose measured by Raemy and Ottaway (1991) using the ARC. If we extrapolate to the self-heat rate of $0.02^{\circ} \mathrm{C} / \mathrm{min}$ used by Raemy and Ottaway for the reaction onset and end, the reaction would start near $170^{\circ} \mathrm{C}$ and end near $285^{\circ} \mathrm{C}$ with a measured enthalpy of $-416 \mathrm{~J} / \mathrm{g}$ cellulose. In most of our other ARC experiments with cellulose, the exothermic temperature rise was substantially less than in the experiment provided in Figure 3.2. The reason for our lesser enthalpy is unknown but could arise from differences in the cellulose evaluated, the variability in cellulose decomposition behavior, or experimental variability.

Milosavljevic et al. (1996) summarize measured pyrolysis enthalpies reported in the literature. These values range from an endothermic $+1260 \mathrm{~J} / \mathrm{g}$ cellulose to an exothermic $-1700 \mathrm{~J} / \mathrm{g}$ cellulose and illustrate the effect of conditions and possibly cellulose source or molecular (polymeric) weight on the thermal decomposition of cellulose. These results show the great variability in reaction enthalpies that exist for cellulose decomposition. 


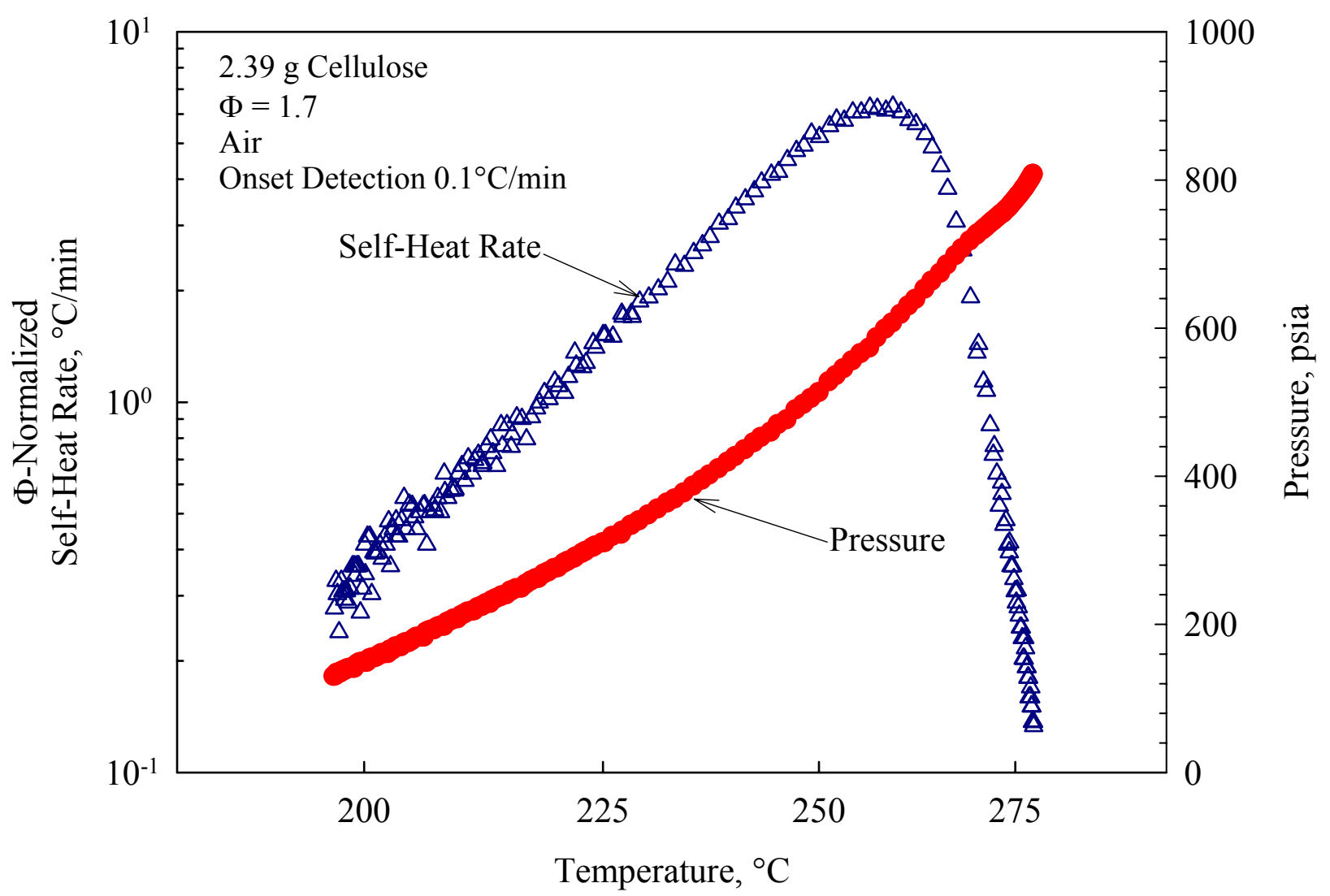

Figure 3.2. Arrhenius Plot of Thermal Behavior of $2.4 \mathrm{~g}$ Cellulose as Measured by ARC with a Titanium Sample Container

For the experiment presented in Figure 3.2, we measured an activation energy of $110 \mathrm{~kJ} / \mathrm{mol}$ and an Arrhenius preexponential of $5.7 \times 10^{11}$ based on the early log linear stages of the ARC-observed reaction. Milosavljevic and Suuberg (1995) summarize activation energies for cellulose thermal decomposition reported in the literature ranging from 109 to $250 \mathrm{~kJ} / \mathrm{mol}$. Antal et al. (1980) noted three types of activation energies in the literature, depending on how the temperature recording devices were coupled to the sample. When the temperature recording device was "decoupled" from the sample, the activation energies ranged from 210 to $250 \mathrm{~kJ} / \mathrm{mol}$. When the coupling was through the gas, the activation energies were between 138 and $210 \mathrm{~kJ} / \mathrm{mol}$, and when directly coupled, the activation energies ranged from 109 to $138 \mathrm{~kJ} / \mathrm{mol}$. Our ARC measurement corresponds to the situation with direct coupling, and our results are similar.

\subsubsection{Thermal Behavior of Sodium Nitrate}

As shown in Figure 3.3, using an onset detection criterion of $0.1^{\circ} \mathrm{C} / \mathrm{min}$, the ARC detected no exothermic reaction between $2.1 \mathrm{~g} \mathrm{NaNO}_{3}$ and its titanium container until $240^{\circ} \mathrm{C}$. The ARC observed $\mathrm{NaNO}_{3}$ 's melting at $308^{\circ} \mathrm{C}$, which is indicated by the decreasing self-heat rate beginning at $308^{\circ} \mathrm{C}$. The exothermic reaction begins again after completion of the endothermic melting event. The reaction continued until the experiment ended at $450^{\circ} \mathrm{C}$. The self heat rates do not rise above $0.7^{\circ} \mathrm{C} / \mathrm{min}$. The pressure increase was 
less than would be predicted based on the temperature increase, assuming ideal gas behavior; we have no explanation for this deviation from ideality.

This experiment shows that $\mathrm{NaNO}_{3}$ or its decomposition products can react with titanium, beginning near $240^{\circ} \mathrm{C}$ and continuing to react up to $450^{\circ} \mathrm{C}$. The log-linear nature of the self-heat rate indicates that the reaction mechanism remains constant throughout the reaction. With respect to our feed ARC experiments, the $\mathrm{NaNO}_{3}$ /titanium reaction could contribute to the measured reaction enthalpy if no other reaction is simultaneously occurring. However, the amount of $\mathrm{NaNO}_{3}$ in this experiment is a factor of 7 greater than the $0.3 \mathrm{~g} \mathrm{NaNO}_{3}$ present in the simulated $\mathrm{BV}$ feed samples discussed in Section 3.1.5. Also in this experiment, the $\mathrm{NaNO}_{3}$ was in intimate contact with the titanium in contrast to the $\mathrm{BV}$ feed samples where the nitrate would be distributed within the other constituents.

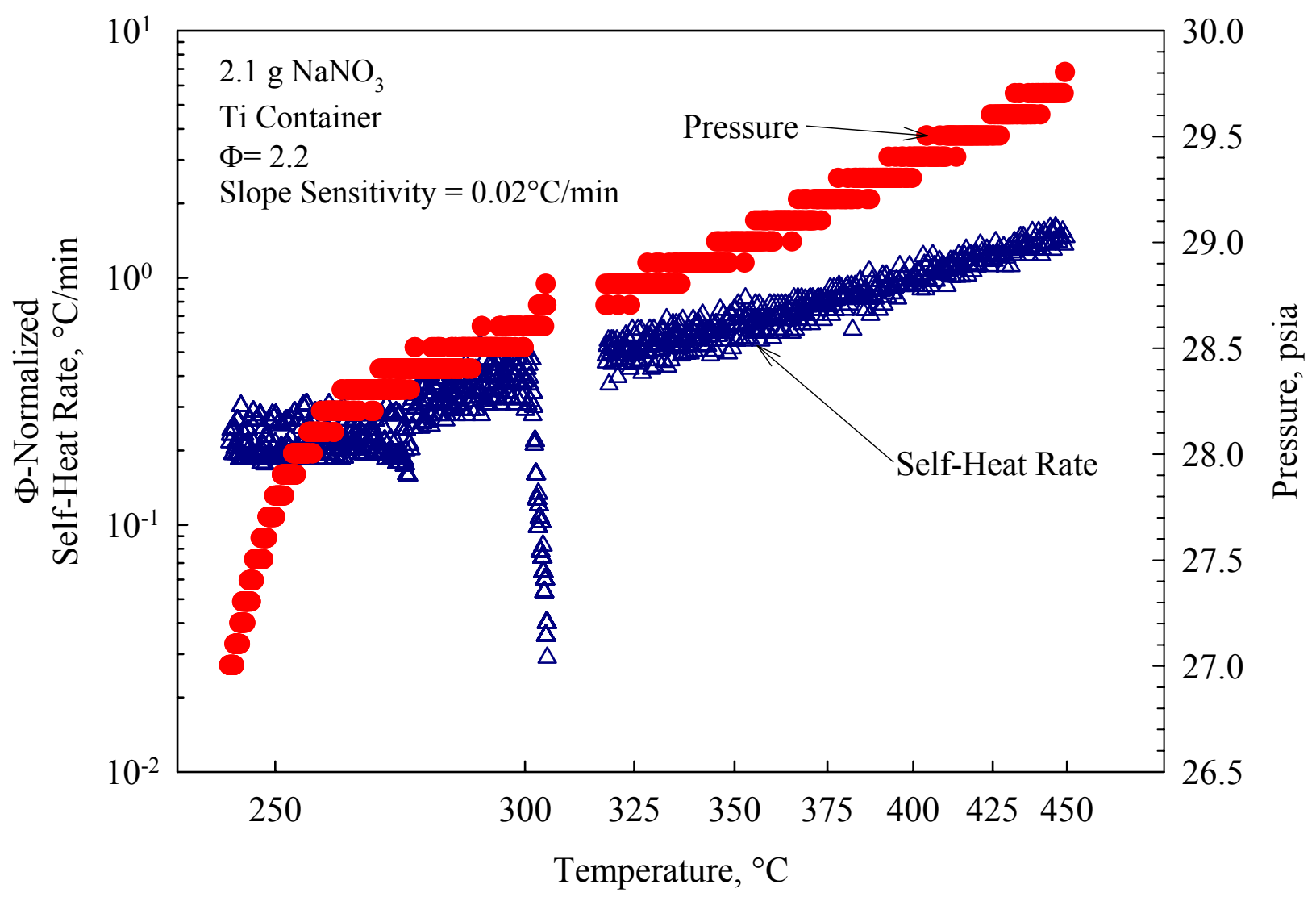

Figure 3.3. Thermal Behavior of $2.1 \mathrm{~g}$ Sodium Nitrate as Measured by ARC in a Titanium Sample Container

\subsubsection{Thermal Behavior of Sodium Nitrate and Cellulose Mixtures}

To help understand the reaction between sodium nitrate and cellulose and the aggregate influences of the other waste constituents on the reaction between nitrate and cellulose in the BV feed, we measured the thermal behavior of three freeze-dried mixtures of sodium nitrate and cellulose using ARC. The first two 
mixtures were 1.3 and $2.5 \mathrm{~g}$ with a $0.75: 1 \mathrm{C}: \mathrm{N}$ ratio equivalent to that planned for the $\mathrm{BV}$ feed, and the third had an excess of cellulose with a 13:1 C:N ratio.

$\mathrm{Wu}$ and Zavarin (1984) used high-pressure DSC and TG to investigate the reaction of various nitrates with a variety of cellulose and other lignocellulosic materials. In general, they discovered exothermic reactions starting between 150 and $200^{\circ} \mathrm{C}$. Wu and Zavarin prepared the cellulosic and nitrate mixtures by mixing the cellulosic material with $1 \underline{\mathrm{N}}$ solutions and then air drying the solids on a filter paper. The peak temperature maxima for the sodium nitrate/microcrystalline cellulose mixture was $276^{\circ} \mathrm{C}$; unfortunately, they reported no reaction enthalpy for the reaction with sodium nitrate.

In our first ARC experiment, presented in Figure 3.4, the 1.2-g sample of cellulose and sodium nitrate $(\mathrm{C}: \mathrm{N}=0.75)$ begins self-heating above $0.1{ }^{\circ} \mathrm{C} / \mathrm{min}$ at $270^{\circ} \mathrm{C}$. The initial reaction continues to $380^{\circ} \mathrm{C}$ where the reaction accelerates dramatically, reaching a self-heat rate of $1700^{\circ} \mathrm{C} / \mathrm{min}$ at $450^{\circ} \mathrm{C}$ at which temperature the experiment terminated. This experiment shows that cellulose and sodium nitrate, based on an onset criterion of $0.1^{\circ} \mathrm{C} / \mathrm{min}$ self-heat rate, begins to react at $270^{\circ} \mathrm{C}$ and will enter thermal runaway under adiabatic conditions at $380^{\circ} \mathrm{C}$.

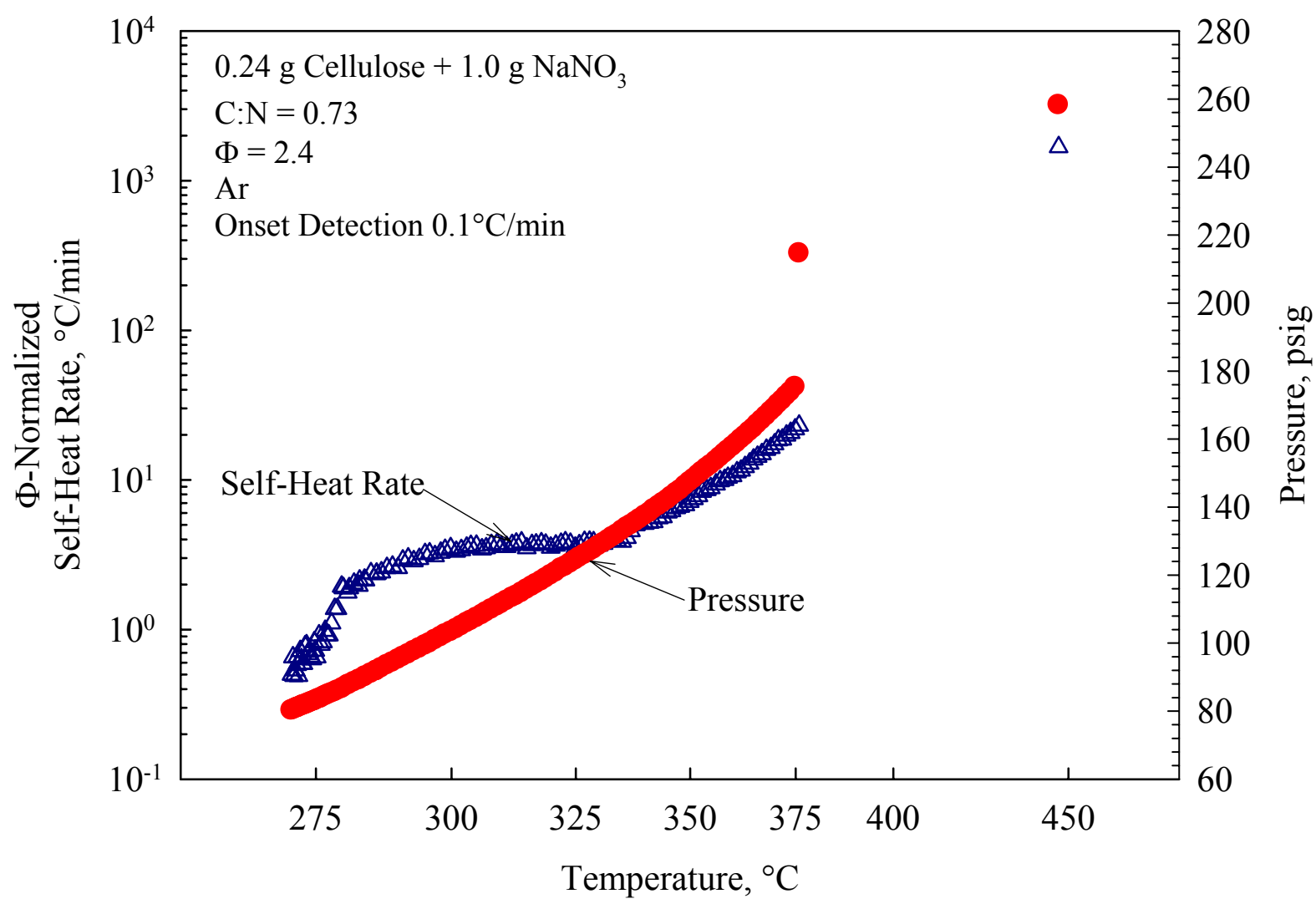

Figure 3.4. Thermal Behavior of a $1.2 \mathrm{~g}$ Mixture of Cellulose and Sodium Nitrate $(\mathrm{C}: \mathrm{N}=0.73)$ as Measured by ARC 
The self-heat rate observed for this reaction $\left(0.2\right.$ to $\left.1700^{\circ} \mathrm{C} / \mathrm{min}\right)$ is significantly greater than the observed 0.1 to $1{ }^{\circ} \mathrm{C} / \mathrm{min}$ for $2 \mathrm{~g}$ sodium nitrate in a titanium container (Figure 3.3), indicating that this reaction is between sodium nitrate and cellulose.

In a second experiment to provide a greater sensitivity for detecting an exothermic reaction, we increased the sample mass while maintaining the same reactant ratio as used in the BV feed. As Figure 3.5 shows, a short-lived exothermic reaction occurs near $220^{\circ} \mathrm{C}$. A second ARC-observed exothermic reaction (onset criteria $0.1^{\circ} \mathrm{C} / \mathrm{min}$ ) begins at $260^{\circ} \mathrm{C}$ or about $10^{\circ} \mathrm{C}$ less than the observed onset temperature for the $1-\mathrm{g}$ sample (Figure 3.4). The reaction runs away at $290^{\circ} \mathrm{C}$, reaching self-heat rates of at least $150^{\circ} \mathrm{C} / \mathrm{min}$; the later actual heating rates are unknown as the containment lost its integrity after $290^{\circ} \mathrm{C}$.

We do not know whether this $225^{\circ} \mathrm{C}$ reaction that occurs at the same temperature as the exothermic decomposition reaction observed for cellulose alone (Figure 3.2) is due to cellulose decomposition or the reaction of cellulose with nitrate. Further testing would be required to assign this reaction to decomposition of the cellulose. We suspect that that the thermal decomposition of cellulose increases its susceptibility to reaction with nitrate in this temperature region.

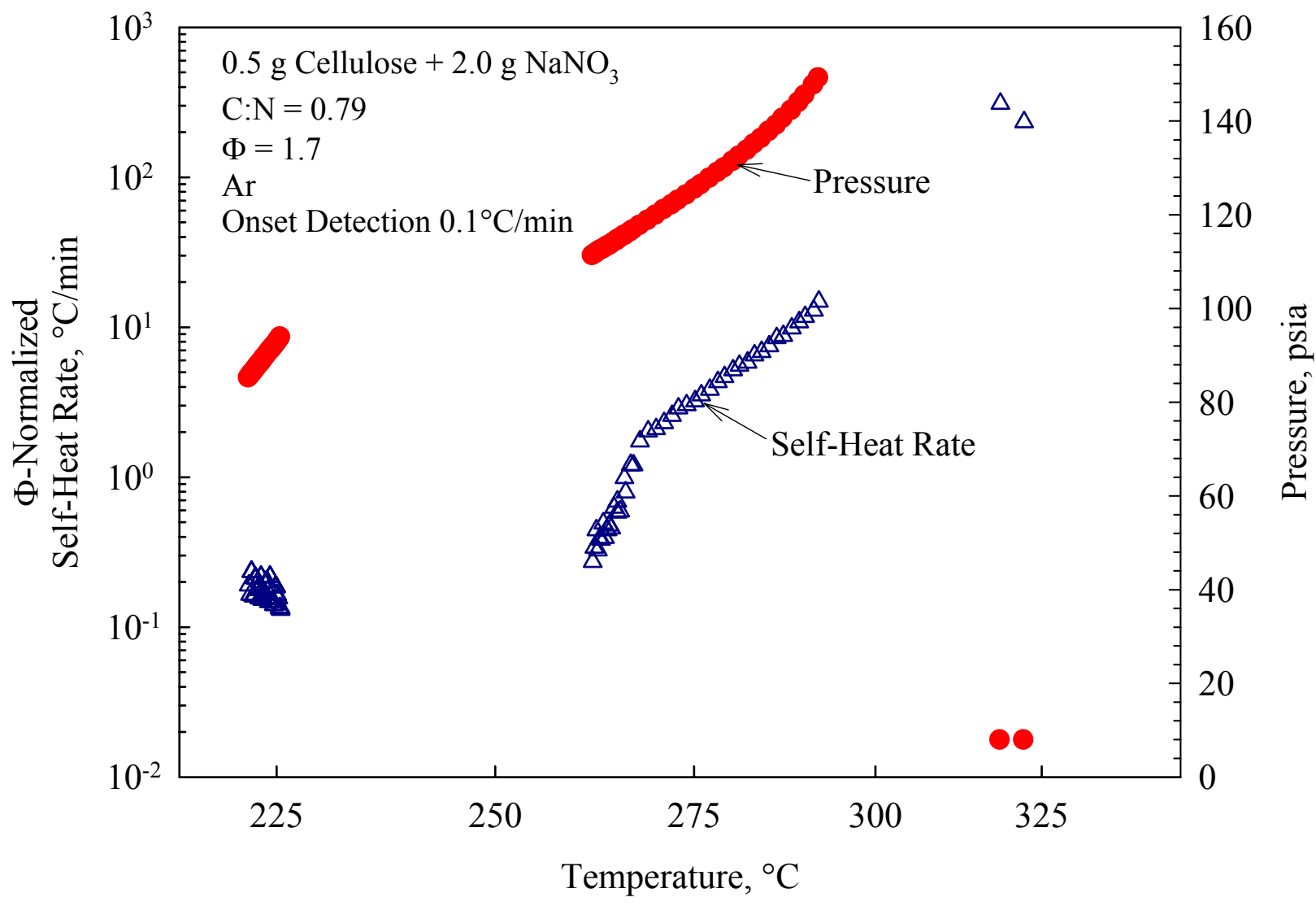

Figure 3.5. Thermal Behavior of a $2.5 \mathrm{~g}$ Cellulose and Sodium Nitrate Mixture $(\mathrm{C}: \mathrm{N}=0.79)$ as Measured by ARC

In the third cellulose/sodium nitrate experiment, we used an excess of cellulose relative to sodium nitrate $(\mathrm{C}: \mathrm{N}=13)$. Inspection of Figure 3.6 finds a reaction beginning (self-heat rate onset criterion $0.1^{\circ} \mathrm{C} / \mathrm{min}$ ) at $190^{\circ} \mathrm{C}$, which is where cellulose thermally decomposes exothermically (Figure 3.2). It is possible that 
thermal decomposition would occur in this instance where there is an excess of cellulose. The reaction nominally ends near $240^{\circ} \mathrm{C}$, but two additional exotherms are observed between 249 and $255^{\circ} \mathrm{C}$, neither of which can sustain a self-heat rate of $0.1^{\circ} \mathrm{C} / \mathrm{min}$. At $265^{\circ} \mathrm{C}$, a reaction begins that accelerates near $290^{\circ} \mathrm{C}$ to a peak rate of $1000^{\circ} \mathrm{C} / \mathrm{min}$ at $340^{\circ} \mathrm{C}$ where the reaction stops; the ARC unexplainably stopped and did not proceed to heat to its target final temperature of $450^{\circ} \mathrm{C}$.

The ARC-measured reaction enthalpy was $-2600 \mathrm{~kJ} /$ mole cellulose compared to the predicted -1872 $\mathrm{kJ} /$ mole cellulose reaction enthalpy calculated assuming Smith et al.'s stoichiometry. It was assumed that 1) the reaction in Figure 3.6 is continuous between 190 and $360^{\circ}$ and has a $C_{p}$ of $2 \mathrm{~J} / \mathrm{g}$ mix and a $\Phi$ of 2.8 and 2) each mole of $\mathrm{NaNO}_{3}$ consumes 0.17 mole cellulose. In this experiment, we measured $1.4 \mathrm{~J}$ per maximum predicted $\mathrm{J}$.

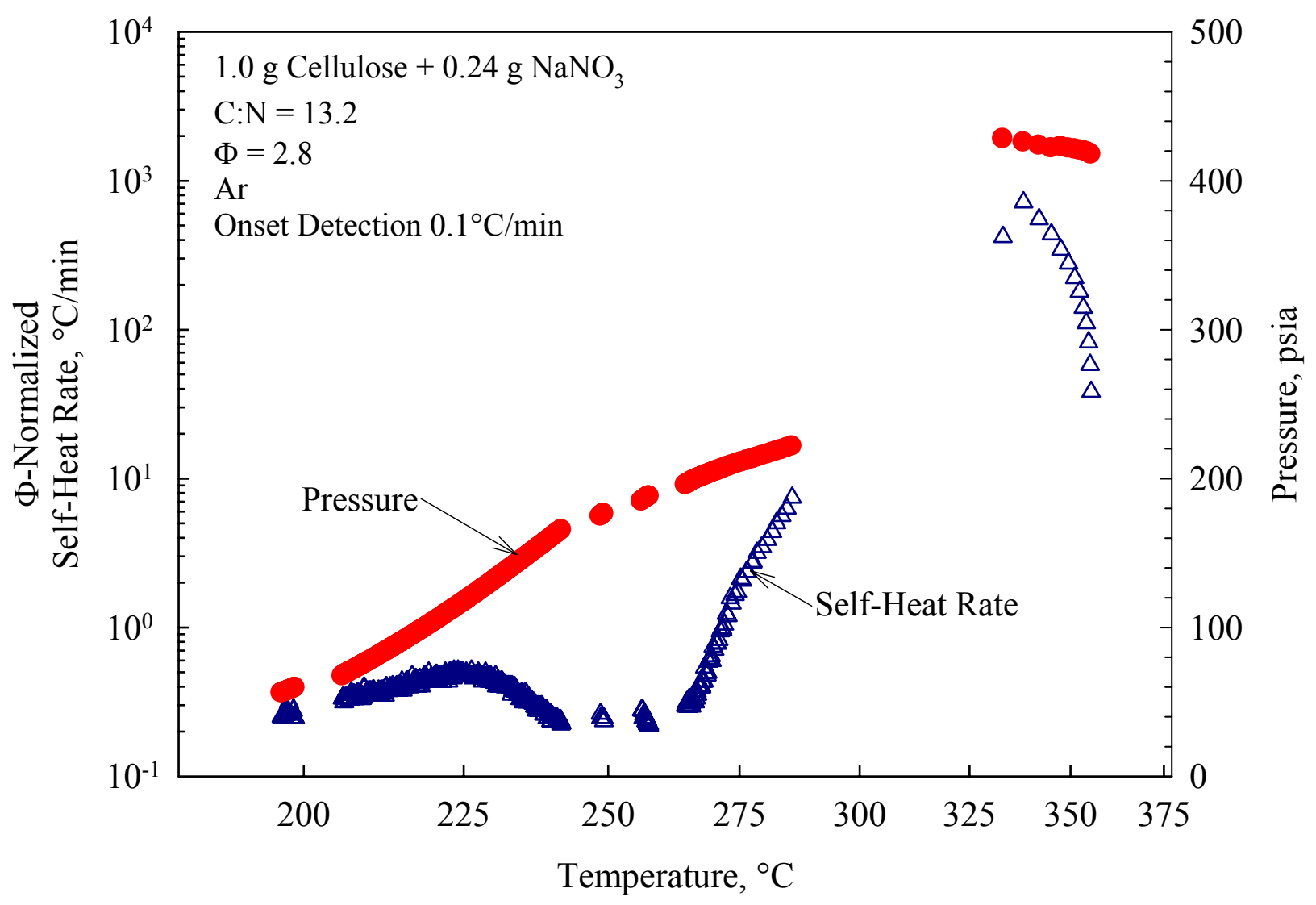

Figure 3.6. Thermal Behavior of a Mixture of $1.2 \mathrm{~g}$ Cellulose and Sodium Nitrate $(\mathrm{C}: \mathrm{N}=13)$ as Measured by ARC

Factors that could affect our reaction enthalpy measurement include 1) the near $1000^{\circ} \mathrm{C} / \mathrm{min}$ self-heating rate after $290^{\circ} \mathrm{C}$, which exceeds the ARC's ability to maintain adiabatic conditions above a self-heating rate of $15^{\circ} \mathrm{C} / \mathrm{min}, 2$ ) our use of an onset detection sensitivity of $0.1^{\circ} \mathrm{C} / \mathrm{min}$ compared to a more sensitive $0.02^{\circ} \mathrm{C} / \mathrm{min}, 3$ ) our ignoring the enthalpy for sodium nitrate melting, and/or 4) a different reaction mechanism than Smith et al.'s postulated reaction mechanism. Our thermodynamic calculations of various stoichiometries indicate that Smith et al.'s stoichiometry yields the largest reaction enthalpy. With the exception of a different reaction stoichiometry, all of these factors would cause our measurement 
of the reaction enthalpy to be less than the maximum theoretical reaction enthalpy. The potential complexity of cellulose thermal behavior may further complicate the comparison of the predicted and measured enthalpies.

We do not have an explanation for the difference between our ARC-measured and predicted maximum reaction enthalpy. Without additional measurements using methods to increase the heat capacity of the sample to slow the reaction, it is not possible to make inferences regarding the ability of the ARC to measure the reaction enthalpy of the cellulose-nitrate reaction.

In summary, the cellulose-nitrate experiments indicate that the reaction between sodium nitrate and cellulose is a multi-step process that begins at less than $200^{\circ} \mathrm{C}$. With the sample sizes tested, in several instances, the reactions stopped but restarted with a small amount of ARC-supplied heat. Once temperatures reach $290^{\circ} \mathrm{C}$, under adiabatic conditions, the reaction will thermally run away.

\subsubsection{Thermal Behavior of Simulated Waste as Measured by TGA/DTA}

The TGA/DTA-measured thermal behavior of the simulated S-109 waste is provided in Figure 3.7. In the simulated S-109, we expect endothermic melting reactions, endothermic thermal decompositions such as the dehydration of hydrates, and exothermic reactions between the organic salts sodium acetate as well as nitrate and nitrite, as has been observed in earlier work (Scheele et al. 1995; Wahl et al. 1996). The thermal behavior of the cellulose-loaded feed should be a complex combination of endothermic thermal decompositions and thermally induced exothermic reactions.

As shown in Figure 3.7, simulated S-109 waste finishes losing its physisorbed water near $150^{\circ} \mathrm{C}$ with a second lesser and simultaneous reaction beginning near $100^{\circ} \mathrm{C}$; the DTA suggests reactions are occurring at this temperature, but whether endothermic or exothermic is not possible to distinguish. This second reaction could be due to loss of chemically bound water if endothermic. The DTA suggests that a significant endothermic reaction begins near $200^{\circ} \mathrm{C}$, which is likely sodium nitrate/nitrate melting; sodium nitrate melts at $308^{\circ} \mathrm{C}$, but this melting can be depressed by other materials (e.g., equimolar sodium nitrate/nitrite melts near $210^{\circ} \mathrm{C}$ ). The mass curve and the DTG show a mass increase at $290^{\circ} \mathrm{C}$ followed by a mass loss followed by another mass loss ending by $310^{\circ} \mathrm{C}$. This indicates that a non-melt reaction is occurring simultaneously with the melting. This type of behavior is often characteristic of a simultaneous rapid exothermic reaction. If this is occurring, it is likely the reaction between acetate and nitrate/nitrite. The total mass loss was about $4 \mathrm{wt} \%$ to $500^{\circ} \mathrm{C}$.

\subsubsection{Thermal Sensitivity of Cellulose-Spiked ES-31F Feed as Measured by TGA/DTA}

The first TGA/DTA trial runs used the pelletized ES-31F feed material. The pellets varied in size from several $\mathrm{mm}$ to sub-millimeter diameters. The mass loss varied from run to run between 3 and $20 \mathrm{wt} \%$. To eliminate this apparent sample inhomogeneity, a second batch of ES-31F feed was prepared and ground using a mortar and pestle. 


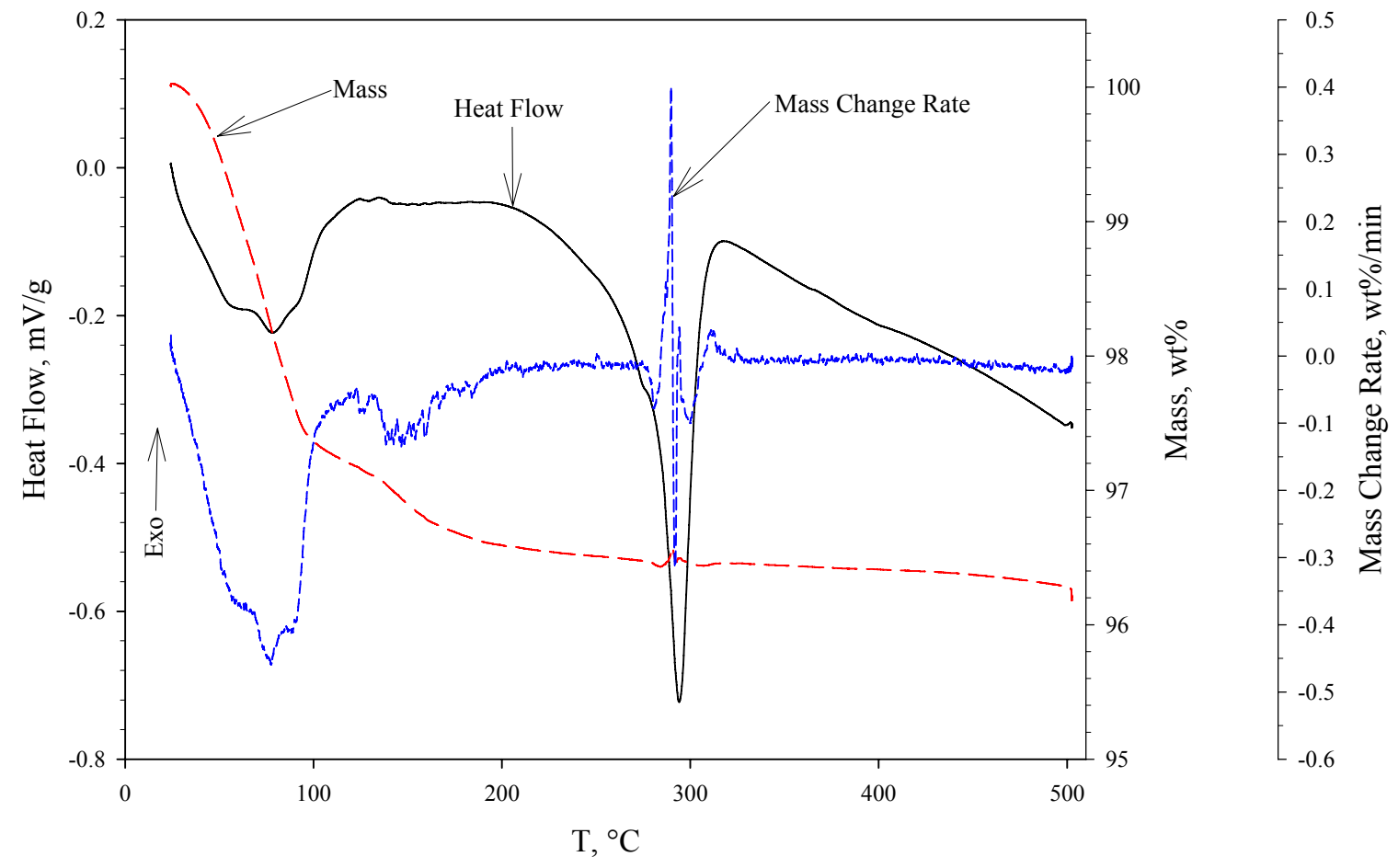

Figure 3.7. Thermal Behavior of Simulated S-109 Waste Used for Testing as Measured by TGA/DTA

This new sample was obtained by taking an entire batch of material from the 22-liter dryer (about $12 \mathrm{~kg}$ of material) and passing it though a splitter multiple times to obtain the final sample provided for these tests. The process assured that the sample was representative of the batched ingredients. The sample was crushed in a large ceramic mortar and pestle to a talc-like powder consistency to assure that the relatively small samples ( 1 to $6 \mathrm{~g}$ ) used for the ARC and very small samples $(20 \mathrm{mg})$ used in the TG/DTA tests were representative of a homogeneous feed.

For this scoping study, we performed six TGA/DTA analyses of 20-mg samples at heating rates of 2, 5, 10,15 , and $20^{\circ} \mathrm{C} / \mathrm{min}$ with one duplicate at $5^{\circ} \mathrm{C} / \mathrm{min}$. Figure 3.8 shows the results of four mass-loss measurements and one DTG, and Figure 3.9 provides the analogous thermal behavior of the ES-31F as measured by DTA at heating rates ranging from 2 to $20^{\circ} \mathrm{C} / \mathrm{min}$.

The TGA/DTA results indicate that the reaction of the organics with nitrate/nitrite in the ES-31F feed proceeds via a multi-step mechanism. An inspection of Figure 3.8 and Figure 3.9 shows a steady mass loss totaling about $4 \mathrm{wt} \%$ by $200^{\circ} \mathrm{C}$, which we attribute principally to the release of physisorbed water. Using the $5^{\circ} \mathrm{C} / \mathrm{min}$ DTG as the guide for the thermal behavior of the ES-31F feed, the DTG indicates a small mass loss near $130^{\circ} \mathrm{C}$, which does not have a corresponding observed enthalpy change in the DTA; this is likely because the DTA is less sensitive. Near $190^{\circ} \mathrm{C}$, a significant exothermic nominal $8 \%$ mass loss begins, continuing until about $320^{\circ} \mathrm{C}$ when a second exothermic reaction begins. It is valuable to note that the expected endothermic melting of the sodium nitrate $\left(\mathrm{mp} 310^{\circ} \mathrm{C}\right)$ is essentially absent or not observed; the melting endotherm could be missing because the exothermic behavior overwhelms its detection, or the nitrate has been significantly destroyed. Near $410^{\circ} \mathrm{C}$, a third exothermic reaction begins and continues to $500^{\circ} \mathrm{C}$. The mass loss that occurs after $500^{\circ} \mathrm{C}$ is likely due the evaporation or 
decomposition of residual $\mathrm{NaNO}_{3}$. Differences in the different heating-rate curves arise from kinetic factors that we use to provide kinetic parameters for the $290^{\circ} \mathrm{C}$ onset major gas-producing reaction.

It is interesting to note that the Raemy and Ottaway (1991) observed exothermic decomposition of cellulose in closed systems was not observed in these purged TGA/DTA experiments. Additional studies would be required to understand the mechanisms causing the differences.

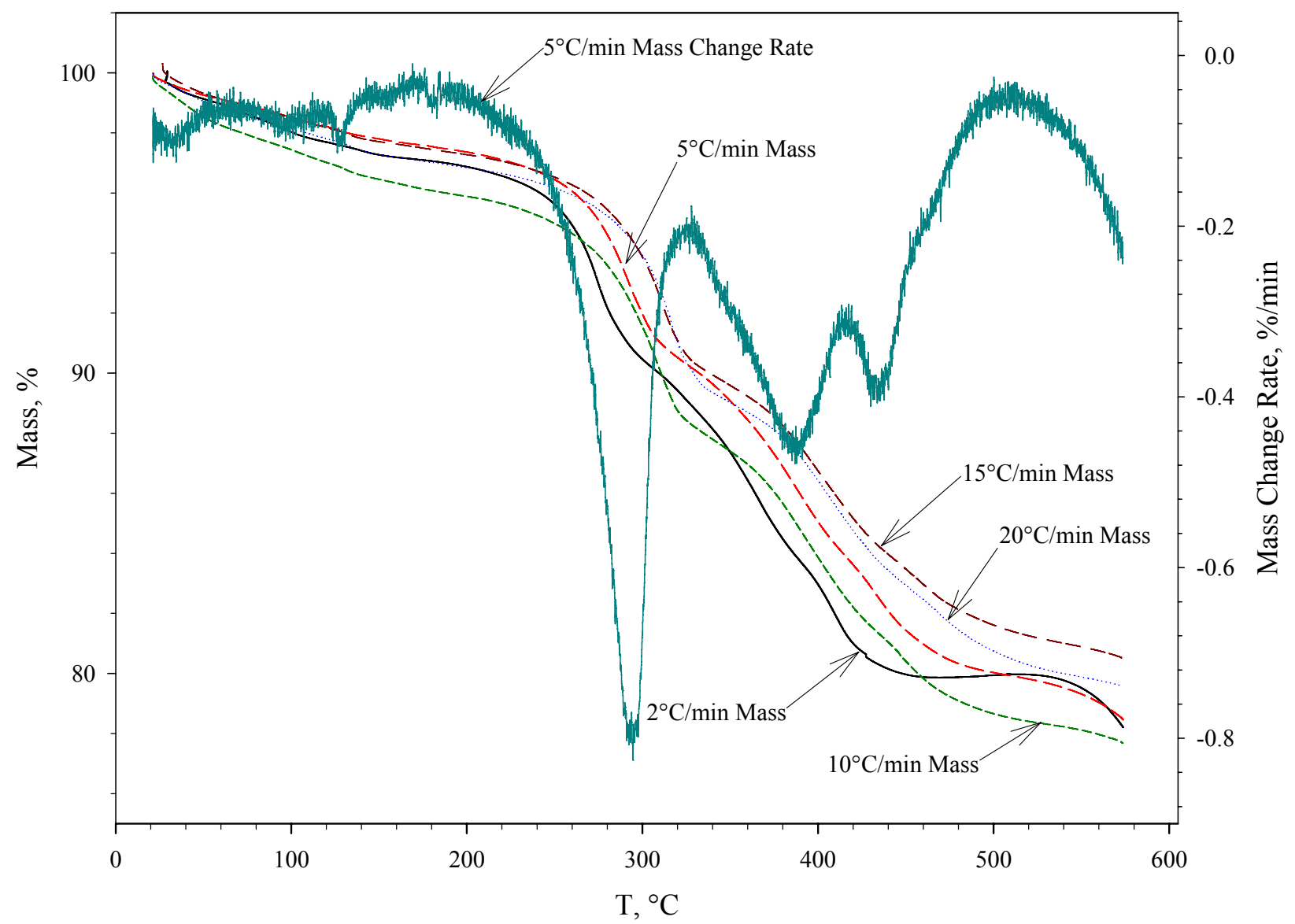

Figure 3.8. Thermal Behavior of Simulant ES-31F Feed as Measured by TGA at Heating Rates of 2 to $20^{\circ} \mathrm{C} / \mathrm{min}$ (includes single DTG)

Table 3.1 shows the mass losses at the different heating rates for the various reaction temperature ranges. The reproducibility in the mass data was good considering the complexity of the simulated feed. The mass loss was $21.4( \pm 1.1) \mathrm{wt} \%$ compared to a predicted $15.6 \mathrm{wt} \%$ mass loss for a 0.75 mole $\mathrm{C} / \mathrm{mole} \mathrm{N}$ assuming Smith et al.'s (1999) postulated stoichiometry. The observed difference likely is due to the nominal $2 \mathrm{wt} \%$ loss up to $100^{\circ} \mathrm{C}$, which is likely free-water loss, but could be due to a different reaction stoichiometry; additional study would be required to fully explain this behavior. 


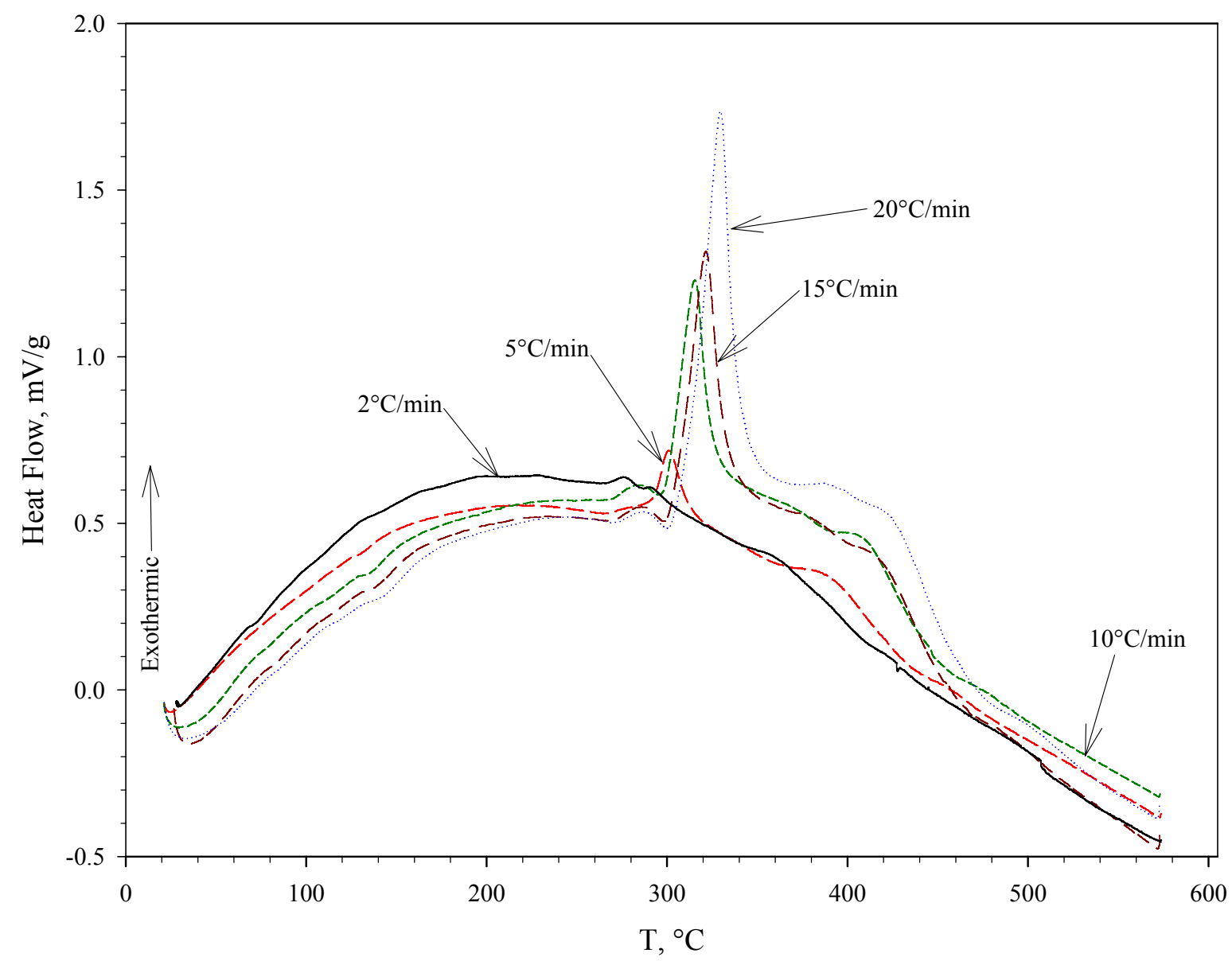

Figure 3.9. Thermal Behavior of ES-31F Feed as Measured by DTA at Heating Rates Ranging from 2 to $20^{\circ} \mathrm{C} / \mathrm{min}$

Table 3.1. Cumulative Mass Loss from Thermal Cellulose Denitration of the ES-31F Feed

\begin{tabular}{|c|c|c|c|c||}
\hline $\begin{array}{c}\text { Heat Rate, } \\
{ }^{\circ} \mathbf{C} / \mathbf{m i n}\end{array}$ & $\begin{array}{c}\text { Initial Mass, } \\
\mathbf{~ m g}\end{array}$ & $\begin{array}{c}\text { Mass Loss } \\
\mathbf{1 0 0}^{\circ} \mathbf{C}, \mathbf{w t} \%\end{array}$ & $\begin{array}{c}\text { Mass Loss, } \\
\mathbf{3 2 0}^{\circ} \mathbf{C}, \mathbf{w t} \%\end{array}$ & $\begin{array}{c}\text { Mass Loss } \\
\mathbf{5 5 0}\end{array}{ }^{\circ} \mathbf{C}, \mathbf{w t} \%$ \\
\hline 20 & 22.7030 & 1.8 & 9.2 & 20.7 \\
\hline 15 & 20.9443 & 1.8 & 9.1 & 20.2 \\
\hline 10 & 23.8371 & 1.5 & 9.5 & 22.6 \\
\hline 5 & 24.1716 & 1.5 & 9.5 & 22.5 \\
\hline 2 & 20.4295 & 2 & 11 & 21.3 \\
\hline Average & $\mathbf{2 2 . 4 1 7 1}$ & $\mathbf{1 . 7}$ & $\mathbf{9 . 7}$ & $\mathbf{2 1 . 5}$ \\
\hline
\end{tabular}

Table 3.2 shows the DTA-measured enthalpies, which average to $-0.23 \mathrm{~kJ} / \mathrm{g}$ feed. Because the reaction between cellulose and nitrate produces significant amounts of gas, 2 mole gas $/$ mole $\mathrm{NaNO}_{3}$, significant amounts of heat will be removed with the gas as it leaves the instrument. Thus, the DTA-measured exothermic enthalpy will underestimate the cellulose/nitrate reaction enthalpy; this contrasts with the 
ARC's operation where the gas's latent heat is not lost and will be observed by the ARC. For the Smith et al. (1999) postulated reaction, the theoretical enthalpy would be $-0.84 \mathrm{~J} / \mathrm{g}$ feed or about 3.5 times that measured by DTA. This significant difference is expected because of the removal of the gases and their latent heat; further calculations would be required to estimate the heat removed with the gases. If the $-0.23 \mathrm{~kJ} / \mathrm{g}$ feed is an accurate measure of the reaction enthalpy, the actual reaction stoichiometry would have to differ from Smith et al.'s (1999) stoichiometry.

Table 3.2. DTA-Measured Enthalpies of the Cellulose/Nitrate Reaction in ES-31 Feed Simulant

\begin{tabular}{|c|c|}
\hline Heat Rate, ${ }^{\circ} \mathbf{C} / \mathbf{m i n}$ & $\boldsymbol{\Delta H}, \mathbf{k J} / \mathbf{g}$ Sample \\
\hline 20 & -0.211 \\
\hline 15 & -0.238 \\
\hline 10 & -0.256 \\
\hline 5 & -0.246 \\
\hline 5 & -0.221 \\
\hline 2 & -0.237 \\
\hline$\Delta \mathrm{H}_{\text {solids }}$ & -0.234 \\
\hline
\end{tabular}

Because of the significant heat loss with the released gases, the DTA-measured enthalpy is a poor measure of the energy density of the cellulose/waste-feed mixture. With that caveat, the DTA-measured $-0.23 \mathrm{~kJ} / \mathrm{g}$ feed and the theoretical reaction heat for Smith et al.'s postulated reaction of $-0.84 \mathrm{~kJ} / \mathrm{g}$ feed fall within the CCPS's (Heemskerk et al. 1995) very low and low-risk categories, respectively, (see Table 1.1). If in the very low risk category, the likelihood of a propagating reaction is unlikely. This contrasts with the ARC-measured enthalpy (see Section 3.3).

Because of the significant difference between the theoretical and the DTA-measured enthalpies, the DTA results suggest that exhausting the product gases will significantly reduce the chemical heat added to a vented or exhausted system; this observation is qualified by the very small DTA sample size that permits gases to escape the reaction zone with limited interactions with residual solids. This conclusion assumes that the gases are exhausted at a rate sufficient to prevent deposition of the gas's latent heat to the system.

\subsection{Thermal Behavior of ES-31F Simulated Feed as Measured by ARC}

The ARC is a sensitive tool for observing exothermic-reaction onset temperatures, measuring gas production, measuring reaction energies, and determining whether a reactive chemical system will support self-sustaining reactions that could eventually lead to a thermal runaway. In support of our studies to determine the effects of adding cellulose to reduce nitrate and MIS, we performed three ARC analyses using a small amount of ES-31F feed $(1 \mathrm{~g})$ to provide a full reaction profile up to the ARC's $450^{\circ} \mathrm{C}$ maximum operating temperature without compromising containment; the first experiment had a significant gas release and is not discussed. We also performed a single larger scale experiment $(6 \mathrm{~g})$ to improve our measurement of the low-temperature reaction; we limited the maximum temperature to $220^{\circ} \mathrm{C}$ to assure that we did not compromise the container's integrity.

Raemy and Ottaway (1991) found using high pressure DTA, heat flow calorimetry, and ARC that cellulose decomposes exothermically in inert sealed systems in contrast to open or flow DTA or DSC studies. Using the ARC, they observed this decomposition near $180^{\circ} \mathrm{C}$. Madorsky et al. (1956) found 
that cellulose decomposed, producing tars composed of levogucosan and small amounts of 1,6 anhydro- $\beta$ D-glucofuranose, 5-(hydroxymethyl)-2-furaldehyde, 2-furyl hydroxymethyl ketone, and 1,4: 3.6-

dianhydro- $\alpha$-D-glocopyranose; these tars were $65 \mathrm{wt} \%$ of the original cellulose mass. Dollimore and Hoath's (1981) review of literature on cellulose decomposition reports that over 60 secondary products have been identified.

Table 3.3 provides the initial and final amounts of ES-31F feed, the initial and final pressures, the final temperature, and a description of the final material used in the three experiments. The mass loss and the pressure data provide gas-production information. Each ARC run required 4 to 5 days for completion because the samples' self-heat rates at the lower temperatures were very low $\left(\sim 0.02^{\circ} \mathrm{C} / \mathrm{min}\right)$. No samples exceeded the set threshold pressure of 2000 psia.

Table 3.3. Initial and Final Mass, Temperature, and Pressure Conditions for the ARC Trials

\begin{tabular}{|c|c|c|c|c|c|c|c|}
\hline ARC \# & ${ }^{(a)} m_{i}, g$ & ${ }^{(a)} m_{f}, g$ & $\% \Delta$ & 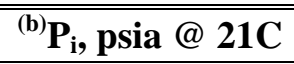 & 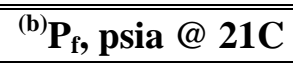 & ${ }^{(\mathrm{c})} \mathbf{T}_{\mathrm{f}}, \mathbf{C}$ & Final color \\
\hline 1 & 0.9993 & 0.873 & 13.1 & 23 & 453 & 450 & light brown \\
\hline 2 & 1.0049 & 0.885 & 11.5 & 22 & 43 & 450 & light brown \\
\hline 3 & 6.4288 & 6.11 & 4.85 & 23 & 44.5 & 220 & grey \\
\hline \multicolumn{8}{|c|}{$\begin{array}{l}\text { (a) } \mathrm{m}_{\mathrm{i}} \text { and } \mathrm{m}_{\mathrm{f}} \text { are the initial and final sample masses. } \\
\text { (b) } \mathrm{P}_{\mathrm{i}} \text { and } \mathrm{P}_{\mathrm{f}} \text { are the initial and final sample pressures. } \\
\text { (c) } \mathrm{T}_{\mathrm{f}} \text { was the final temperature. }\end{array}$} \\
\hline
\end{tabular}

We see from the first ARC experiment, presented in Figure 3.10 and Figure 3.11, that the 1-g ES-31F feed sample began to self-heat near $115^{\circ} \mathrm{C}$, but this 1 -g sample was unable to sustain this initial reaction in its 10 -g container. The instrument heated the sample to nearly $125^{\circ} \mathrm{C}$ where the instrument again observed a self-sustaining exothermic reaction that heated the sample up to near $150^{\circ} \mathrm{C}$ where the selfheat rate declined to the detection criteria of $0.01^{\circ} \mathrm{C} / \mathrm{min}$; this reaction is likely a continuation of the first observed. This barely detectable $150^{\circ} \mathrm{C}$ to nearly $170^{\circ} \mathrm{C}$ reaction was likely a combination of the end of the first reaction and the beginning of the second reaction. Near $170^{\circ} \mathrm{C}$, another reaction began and continued to $275^{\circ} \mathrm{C}$. At $275^{\circ} \mathrm{C}$, a third slower reaction began and continued at least to $390^{\circ} \mathrm{C}$ where the rate again accelerated, indicating the onset of a fourth reaction that continued to the ARC's maximum operating temperature of $450^{\circ} \mathrm{C}$. The fourth exothermic reaction was rapidly accelerating at $4{ }^{\circ} \mathrm{C} / \mathrm{min}$ and producing gases at $15 \mathrm{psia} / \mathrm{min}$ when the ARC terminated the experiment.

In total, this ARC experiment's results are consistent with the DTA results with the exception that the $127^{\circ} \mathrm{C}$ ARC-observed exotherm was not seen by the DTA. The DTA/TGA-observed exotherm beginning at $300^{\circ} \mathrm{C}$ likely corresponded to the 170 to $275^{\circ} \mathrm{C}$ exotherm observed by the ARC. The DTA/TGA observed exotherms beginning at 330 and $410^{\circ} \mathrm{C}$ likely corresponded to the reactions observed by ARC at 275 and $390^{\circ} \mathrm{C}$, respectively. 


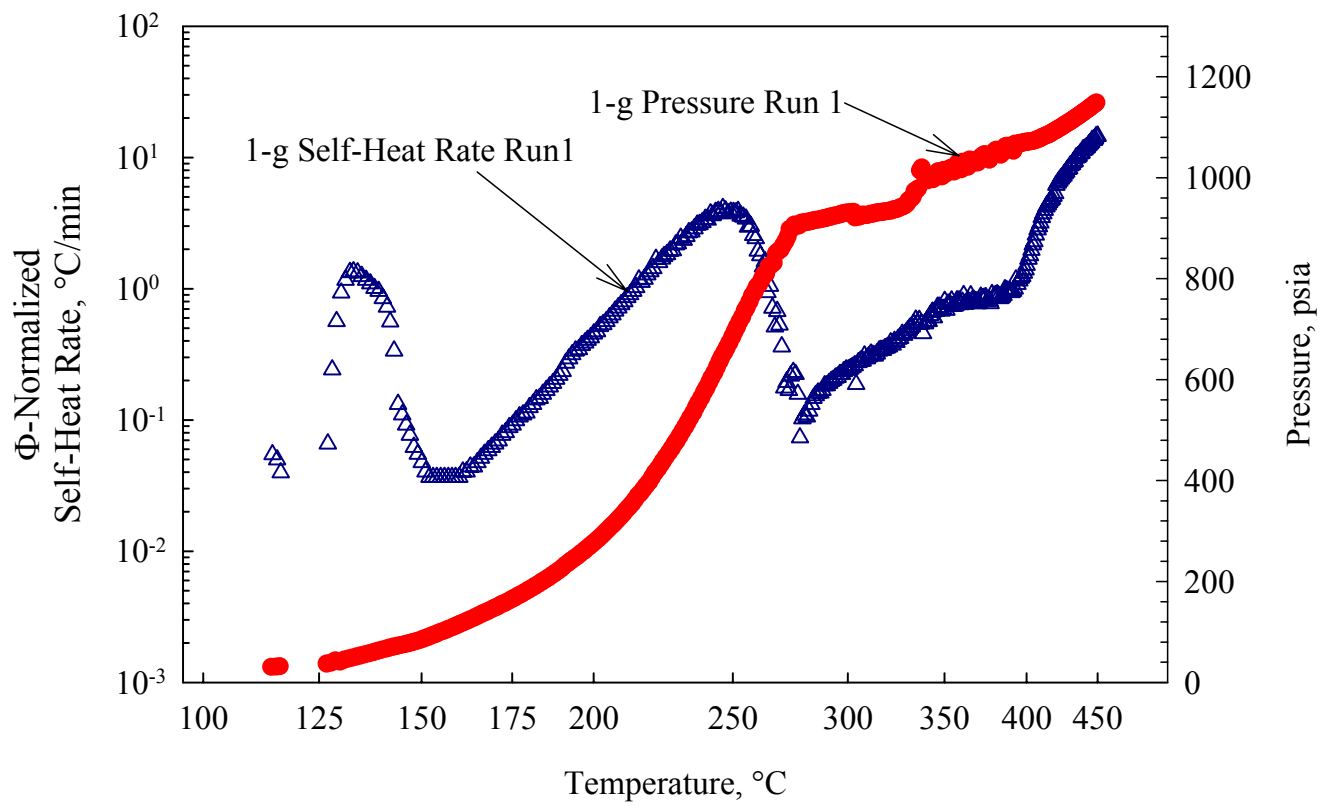

Figure 3.10. Thermal Behavior of $1 \mathrm{~g}$ ES-31F Simulated Feed as Measured by ARC, Experiment \#1

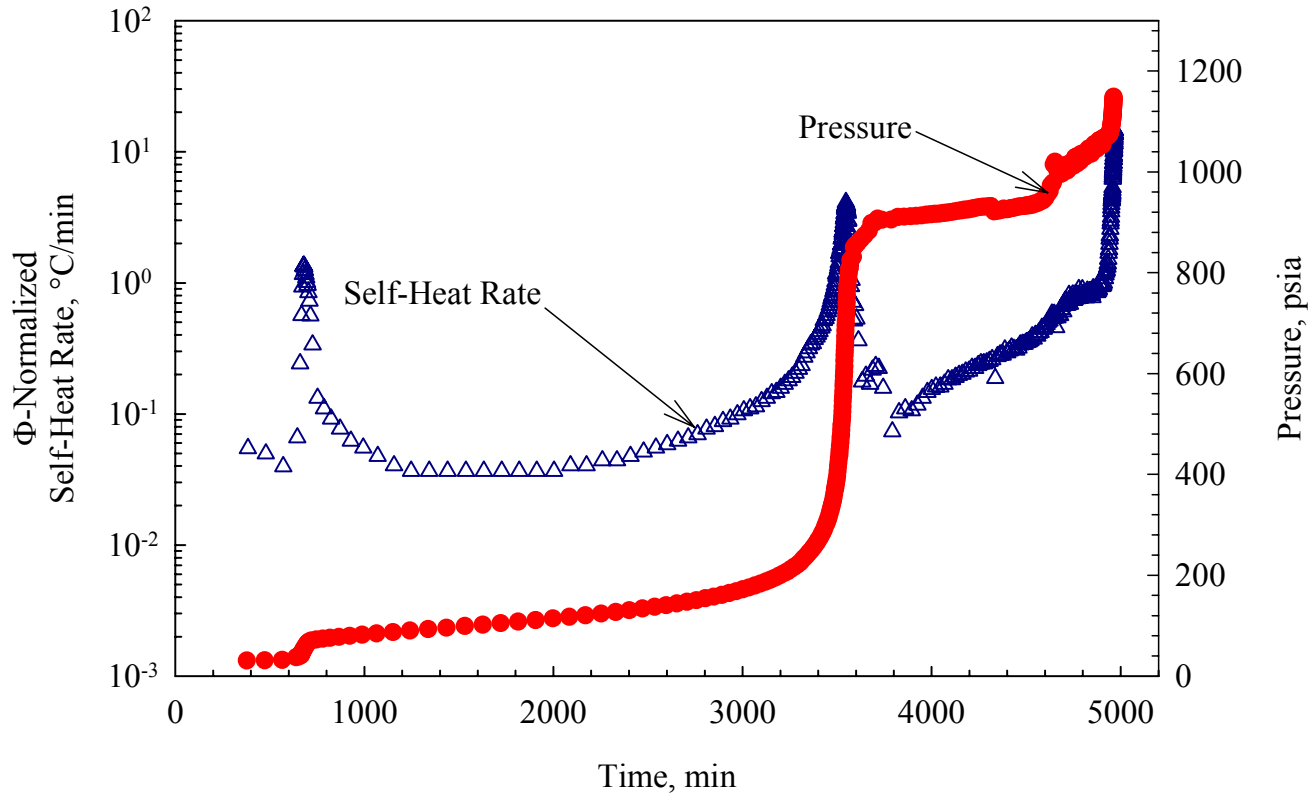

Figure 3.11. Thermal Behavior of $1 \mathrm{~g}$ ES-31F Simulated Feed as a Function of Time as Measured by ARC, Experiment\#1 
The second reaction observed near $170^{\circ} \mathrm{C}$ is near that observed by Raemy and Ottaway (1991) in their $2-\mathrm{g}$ cellulose ARC experiment. Without additional product composition such as obtained through real-time analysis of the product gases or residual solids, we are not able to conclude whether our $170^{\circ} \mathrm{C}$-onset ARC-observed reaction is the same cellulose decomposition as that of Raemy and Ottaway or whether the cellulose decomposition allows reaction with the solid sodium nitrate $\left(\mathrm{mp} 308^{\circ} \mathrm{C}\right)$. Based on our experience, typically, reaction rates with molten salts increase dramatically when a salt melts because of increased reactant mobility.

The third exothermic reaction that begins near $275^{\circ} \mathrm{C}$ occurs in the temperature range where sodium nitrate reacts exothermically with titanium (see Figure 3.3). This raises the possibility that this third reaction was between nitrate and titanium rather than our belief that this reaction was between sodium nitrate and the cellulose char. If this were not a nitrate/char reaction, the calculated reaction enthalpy would be higher than actual, and it could contribute to a higher-than-predicted reaction enthalpy. We believe this observed 275 to $400^{\circ} \mathrm{C}$ reaction is not just the nitrate/container reaction given that 1) the amount of nitrate is a factor of $1 / 7$ of the amount tested in the experiment presented in Figure 3.3, but the self-heat rates are similar (range of $0.5^{\circ} \mathrm{C} / \mathrm{min}$ ), 2) the nitrate is diluted by other waste constituents and intimately mixed with the cellulose-limiting nitrate's access to the titanium container, and 3) a fourth reaction occurs.

The increase in the self-heat rate seen at $400^{\circ} \mathrm{C}$ indicates a fourth reaction that could be due to the reaction of organic gases from cellulose decomposition with the molten nitrate. Further studies would be required to deconvolute the various reactions that are occurring during this experiment.

There are significant differences between the exothermic reactions observed by the ARC for the BV feed and sodium nitrate and cellulose mixtures. The cellulose/sodium nitrate mixtures do not exhibit the reactions observed below $160^{\circ} \mathrm{C}$ even though the feed exhibits self-heating rates above $0.1^{\circ} \mathrm{C} / \mathrm{min}$, which was the onset criterion used for the cellulose/nitrate testing. The second reaction observed for the BV feed begins at a lower temperature than the primary reaction between cellulose and nitrate in the cellulose/nitrate mixtures. The reaction that starts near $280^{\circ} \mathrm{C}$ for both exhibits a similar initial reaction profile, and then when the temperature reaches sodium nitrate's decomposition temperature of $380^{\circ} \mathrm{C}$, the reaction accelerates in both the BV waste feed and the $1.2 \mathrm{~g}$ cellulose/nitrate test. The $2.5 \mathrm{~g}$ cellulose/nitrate mixture began reacting very rapidly at $300^{\circ} \mathrm{C}$ rather than $380^{\circ} \mathrm{C}$. The observed behavior suggests that the waste constituents cause low-temperature reactions, but once the primary sodium nitrate and cellulose reaction begins circa $280^{\circ} \mathrm{C}$, the reaction in the simulated waste feed is dominated by the primary sodium nitrate/cellulose reaction(s).

We see from Figure 3.11, which provides the total pressure and self-heat rate as a function of time, that the principal gas-producing reaction occurs between 2200 and 3800 minutes or between 160 and $275^{\circ} \mathrm{C}$ (from Figure 3.10) and produces about $800 \mathrm{psia}$. The pressure increased further to $1140 \mathrm{psia}$ at $450^{\circ} \mathrm{C}$, the experiment's end. The self-heat rate and gas-release rate were increasing rapidly when the run terminated at $450^{\circ} \mathrm{C}$. The maximum gas-release rate observed for the second exotherm was $0.25 \mathrm{mmol} / \mathrm{g} / \mathrm{min}$. At the termination of the experiment at $450^{\circ} \mathrm{C}$, the maximal gas-release rate had climbed to $0.35 \mathrm{mmol} / \mathrm{g} / \mathrm{min}$. The total pressure increase of $1117\left(\mathrm{P}_{\mathrm{f}}-\mathrm{P}_{\mathrm{i}}\right)$ psia indicates, assuming ideal gas, that $18.9 \mathrm{mmol}$ of gas was released per gram of feed.

The mass loss for this first ARC experiment was $13.1 \mathrm{wt} \%$. The residue was a light-brown powder. The mass-loss data near $450^{\circ} \mathrm{C}$ reported in Table 3.1 from the TG experiments suggests that mass loss should 
be about $20 \mathrm{wt} \%$ compared to the Smith et al. (1999) stoichiometry-based $16.7 \mathrm{wt} \%$ (assuming no water loss other than waters of hydration or decomposition of hydroxides as presented in Table 2.1). The difference between the Smith-predicted loss and this ARC experiment likely arose because the reaction was not allowed to complete in the ARC experiment.

The first ARC experiment indicates that the ES-31F feed will react slowly without producing significant amounts of gas at temperatures as low as $110^{\circ} \mathrm{C}$. Although this low-temperature reaction slows to barely detectable self-heating rates for the 1-g sample and 10-g container continuously to the onset of the next reaction, this experiment suggests that if the initial reaction begins, it will produce sufficient heat to begin a second reaction near $170^{\circ} \mathrm{C}$ under adiabatic conditions.

The second ARC experiment, presented in Figure 3.12, which used a 7-g sample container, found similar thermal behavior as the first experiment with 1) a self-sustaining reaction beginning near $120^{\circ} \mathrm{C}, 2$ ) a second reaction beginning to accelerate near $200^{\circ} \mathrm{C}$, and 3) a third reaction starting near $310^{\circ} \mathrm{C}$. We believe the differences between the first and second ARC experiments were caused by a container seal that failed in the second experiment to retain the product gases, subsequently compromising its absolute results. Because of the suspected gas loss during the second experiment, the two experiments are not directly comparable, and the second is provided in this report to provide qualitative confirmation of the behavior observed by the first ARC experiment.

In the second ARC experiment, the self-heat rates do not reach those of the first analysis, and the pressure is significantly lower: 120 psia vs 1120 psia in the first. The 120 psia final pressure indicates, assuming ideal gas, that $1.65 \mathrm{mmol}$ gas was produced or an order of magnitude less gas than in the first experiment. The less-than-expected pressure increase relative to the first ARC analysis suggests that a leak in the system occurred, resulting in the loss of heat with the gases. The suspect gas release likely accounts for the lesser magnitude of the exotherms near $160^{\circ} \mathrm{C}$ and $325^{\circ} \mathrm{C}$.

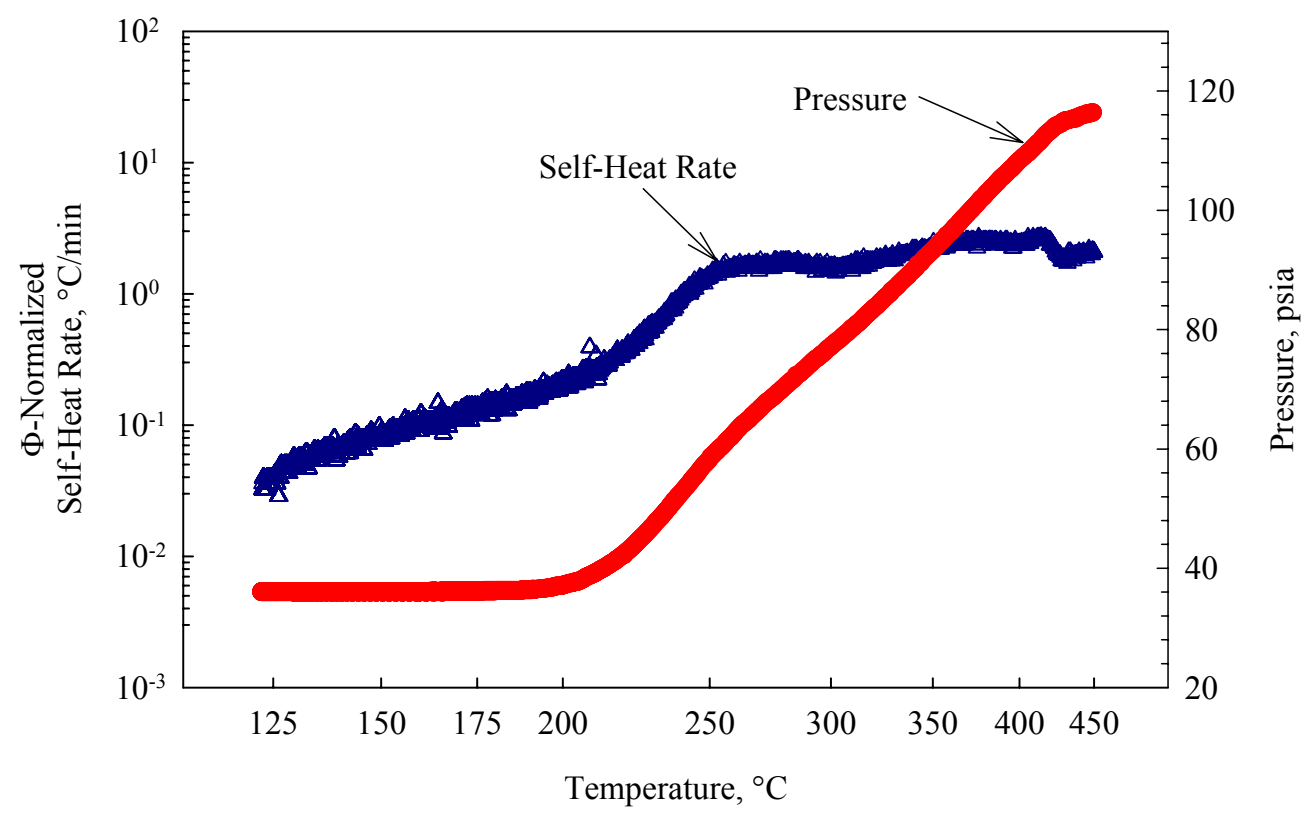

Figure 3.12. Thermal Behavior of $1 \mathrm{~g}$ Simulated ES-31F Feed as Measured by ARC, Experiment \#2 
After ARC trial ${ }^{\#} 2$ had cooled, the room-temperature pressure reading was 43 psia. This pressure was maintained for at least 1 hour before collecting the gases from the titanium sample container for characterization by IR and MS. The apparent leak was not obvious at this temperature.

The sample lost $11.5 \mathrm{wt} \%$ with the residue becoming a light-brown powder. This is slightly lower than the previous ARC analysis ( $13.1 \mathrm{wt} \%$ loss) and less than the $16.7 \mathrm{wt} \%$ that would be predicted using Smith et al.'s (1999) postulated reaction stoichiometry without any free moisture evaporation. The mass loss indicates that the gas production should be similar between the two ARC experiments, but since they are not, this indicates that the second ARC experiment was compromised by the loss of gas.

This second ARC experiment again shows that self-sustaining reactions begin near $120^{\circ} \mathrm{C}$ with little gas production. The reaction for the 1-g sample did not sustain heating of the sample and its 7-g container until the next larger significant gas-producing reaction begins. This experiment with its apparent loss of gas suggests that even with the loss of heat through loss of the gases, the ES-31F feed will support selfsustaining reactions that can lead to elevated temperatures.

The third ARC run, which was designed to improve the measurement of the lower temperature reaction's onset temperature, used a larger sample size of 6.4288 grams of the ES-31F feed. To make sure that containment was maintained, we limited the maximum temperature to $225^{\circ} \mathrm{C}$. The results of this larger scale experiment are provided in Figure 3.13.

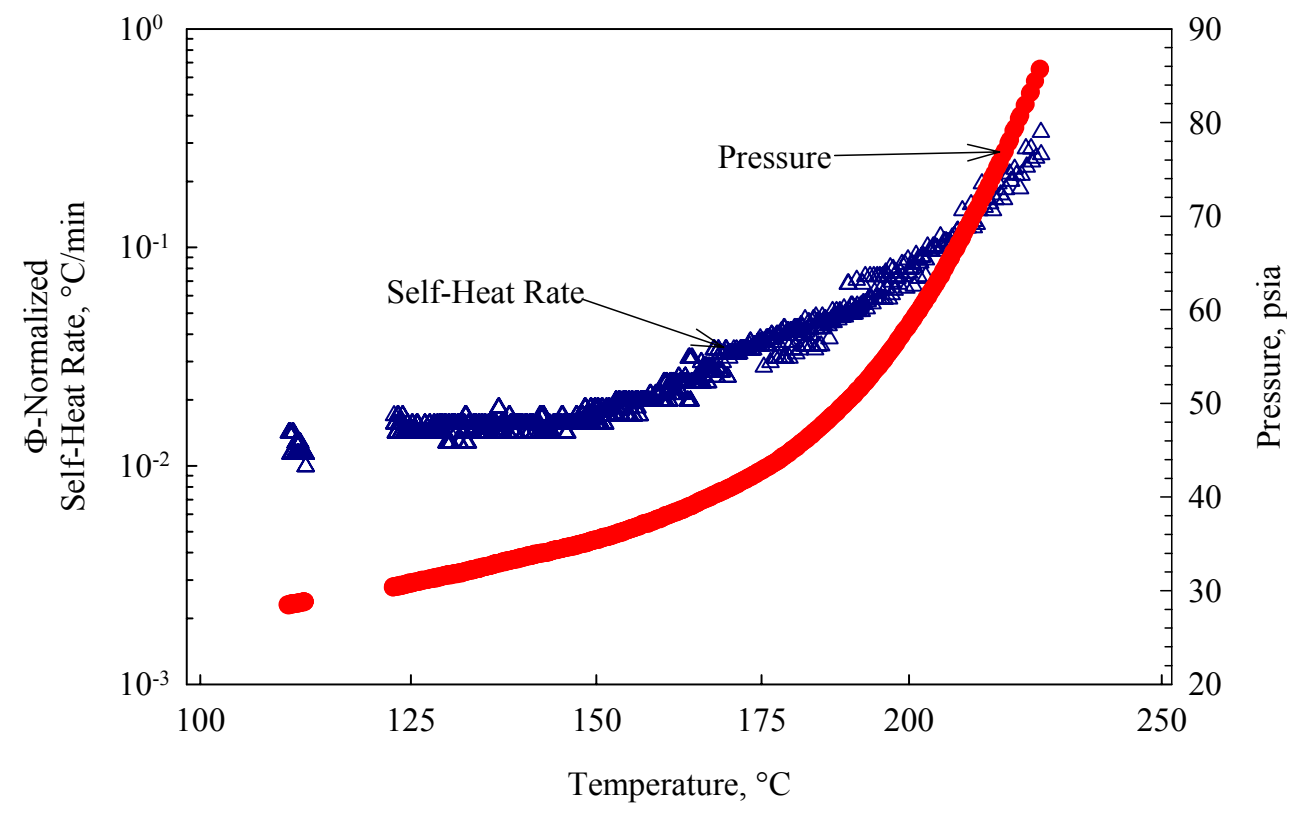

Figure 3.13. Thermal Behavior of 6-g ES-31F Feed Sample as Measured by ARC up to $225^{\circ} \mathrm{C}$

Figure 3.13 shows that the 6-g sample of ES-31F begins to react at $110^{\circ} \mathrm{C}$, stops, and begins a selfsustaining reaction at $120^{\circ} \mathrm{C}$, which continues to heat the sample up to the experiment's end at $220^{\circ} \mathrm{C}$ under adiabatic conditions. This $110^{\circ} \mathrm{C}$ onset exothermic behavior is lower than the near $180^{\circ} \mathrm{C}$ that Raemy and Ottaway (1991) in their 2-g ARC experiment and Scheele et al. (2005) observed. This difference and our earlier ARC experiments indicate that this initial reaction is different from the 
exothermic cellulose decomposition observed by Raemy and Ottaway and Scheele et al. (2005). The mass difference (6 g vs $2 \mathrm{~g}$ ) between this work and Raemy and Ottaway's work is not sufficient to explain their not seeing it. We therefore have to attribute the reaction to the cellulose being in the ES-31F waste matrix.

Comparison of this 6-g ARC experiment with the first 1-g ARC experiment (Figure 3.10) finds the $120^{\circ} \mathrm{C}$-onset reaction peaking at $125^{\circ} \mathrm{C}$ with a self-heat rate of $1{ }^{\circ} \mathrm{C} / \mathrm{min}$ missing from this 6 -g experiment's results. Figure 3.13 indicates that a single continuous reaction, which we believe is likely the $170^{\circ} \mathrm{C}$-onset reaction observed for the 1 -g experiment (Figure 3.10 ), begins at $110^{\circ} \mathrm{C}$ and continues to temperatures above $220^{\circ} \mathrm{C}$. We do not have an explanation for this significant difference in behavior because the larger sample mass and a less-massive sample container (smaller $\Phi$-factor 5 vs 1.4, respectively) should lead to greater instrument sensitivity as illustrated by the ARC's determination of a lower onset temperature. These results highlight the need for scale-up calculations and evaluations based on operating parameters and system kinetics.

The $4.58 \mathrm{wt} \%$ mass-loss reaction produced a light-grey residue compared to the light-brown residues of ARC runs ${ }^{\#} 1$ and 2 . This last residue had an odor akin to heavy organic carbohydrates, which would be consistent with the large variety of secondary volatile pyrolysis products mentioned by Dollimore and Hoath (1981).

In summary, the ARC experiments indicate that under adiabatic conditions, a self-sustaining reaction begins near $110^{\circ} \mathrm{C}$, and, once started, the system will self-heat to significant temperatures, producing significant amounts of gas. The sealed bomb used in our ARC experiments shows pressure increases of over $1000 \mathrm{psia}(60 \mathrm{~atm})$ and temperature increases of around $300^{\circ} \mathrm{C}$ as a result of the denitration and/or cellulose decomposition reaction(s). Additionally, the ARC results indicate that the reaction occurs in multiple steps and shows periods of intense pressure and temperature increase $\left(15 \mathrm{psi} / \mathrm{min}\right.$ and $5^{\circ} \mathrm{C} / \mathrm{min}$, respectively). This initial reaction is slow on the 1- to 6-g scale. However, the ARC results indicate that if $100^{\circ} \mathrm{C}$ is within $50^{\circ} \mathrm{C}$ of the operating temperature, the behavior of the system should be analyzed using measured reaction rates and thermal conductivities to determine whether or what engineering controls (e.g., cooling systems) are needed or are appropriate for actual batch quantities.

\subsection{Heat Release as Measured by ARC}

To calculate the reaction enthalpy, we used enthalpy's existence as a state function where the final state does not depend on the path. We thus assumed that the reaction proceeded to completion following Smith et al.'s (1999) stoichiometry at the ARC-observed onset temperature with no temperature increase. After reaction completion, we increased the temperature of each individual product to the final ARC temperature $\left(450^{\circ} \mathrm{C}\right)$. Thus, we calculated the reaction enthalpy by summing the enthalpy required to heat each individual product component from the initial temperature (T1) to the final temperature (T2). The enthalpy required to heat the sample container to $\mathrm{T} 2$ and then the enthalpies for phase changes were added. The process is summarized per Equation 3.1.

$$
\Delta H_{r \times n}=\left[\sum_{i}\left(C_{p(s)[i]} \times m_{s[i]}\right) \times \Delta T\right]+\left[\left(C_{p(b)} \times m_{b}\right) \times \Delta T\right]+\Delta H_{P C}
$$


$\mathrm{C}_{\mathrm{p}(\mathrm{s})}, \mathrm{m}_{\mathrm{s},} \mathrm{C}_{\mathrm{p}(\mathrm{b})}$, and $\mathrm{m}_{\mathrm{b}}$ are the average heat capacities at $\mathrm{T} 1$ (measured onset temperature) and $\mathrm{T} 2$ (reaction final temperature) and masses of the sample and sample container, respectively. $\Delta \mathrm{H}_{\mathrm{PC}}$ is the enthalpy change due to a phase change, such as the melting of $\mathrm{NaNO}_{3}$ (pure $\mathrm{NaNO}_{3} \mathrm{mp}=307^{\circ} \mathrm{C}$ ). Because the reaction had not ended when we terminated the ARC experiment, the measured $\Delta \mathrm{H}$ should be less than actual. We used Barin's (1989) heat capacities for the reaction products and the residual inerts. Because the second ARC experiment appears to have developed a gas leak, it is not used for the heat-release results.

Table 3.4. Heat Release as Measured by ARC

\begin{tabular}{|c|c|c|}
\hline Trial & $\Delta \mathbf{T}_{\mathbf{a b}}, \mathbf{K}$ & $\begin{array}{c}\Delta \mathbf{H}, \\
\mathbf{k J} \mathbf{g}^{-\mathbf{1}} \mathbf{F e e d}\end{array}$ \\
\hline 1 & 325 & -2.2 \\
\hline
\end{tabular}

The ARC-measured $\Delta \mathrm{H}-2.2 \mathrm{~kJ} / \mathrm{g}$ feed is significantly greater than the predicted $\Delta \mathrm{H}$ of the $-0.83 \mathrm{~kJ} / \mathrm{g}$ feed based on Smith et al.'s (1999) postulated reaction stoichiometry. If it is assumed that the temperature rise from $275^{\circ} \mathrm{C}$ to $390^{\circ} \mathrm{C}$ is due to the reaction of nitrate with the container, the reaction enthalpy would decrease to about $-1.4 \mathrm{~kJ} / \mathrm{g}$ feed. Our sodium nitrate and cellulose testing suggests that this alone will not explain the difference in behavior since the TG/DTA observes reactions in this temperature range, presumably between nitrate and cellulose or cellulose decomposition or reaction products.

We do not have a definite explanation for this significant difference between the predicted $\Delta \mathrm{H}_{\mathrm{rx}}$ and the ARC-measured $\Delta \mathrm{H}_{\mathrm{rx}}$. Various approaches were attempted relying on enthalpy's state-function status to calculate the $\Delta \mathrm{H}_{\mathrm{rx}}$, including 1) mathematically heating the reactants to the final temperature and then reacting the mixture and 2) using an average $C_{p}$ for the reactants at the reaction onset temperature and the products at the experiment's termination temperature and obtained similar results. We based the predicted reaction enthalpy solely on cellulose's reaction with nitrate and ignored any reactions of other waste constituents between themselves or with the glass formers in the BV feed; this decision is supported by the DTA analyses provided in Figure 3.9 that report no high-temperature exotherms.

We obtained mixed results in our other attempts to measure reaction enthalpies using ARC. Our ARCmeasured $\Delta \mathrm{H}_{\mathrm{rx}}$ for the decomposition of cellulose (Section 3.1.1) was $-420 \mathrm{~kJ} / \mathrm{g}$ cellulose, which is significantly lower than Raemy and Schweizer's (1983) high-pressure DTA-measured $-650 \mathrm{~kJ} / \mathrm{g}$ cellulose and Raemy and Ottaway's (1991) ARC-measured -500 to $-650 \mathrm{~kJ} / \mathrm{g}$ cellulose. Our measured $\Delta \mathrm{H}_{\mathrm{rx}}$ for the cellulose and sodium nitrate reaction with the excess of cellulose was $-2630 \mathrm{~kJ} / \mathrm{mol}$ cellulose versus a predicted $-1890 \mathrm{~kJ} / \mathrm{mol}$ cellulose for Smith et. al.'s postulated mechanism or $1.4 \mathrm{~J}$ measured per J predicted. Our two measures of $\Delta \mathrm{H}_{\mathrm{rx}}$ for the reaction of cellulose and nitrate were consistently higher than predicted. This variability makes it difficult to explain the differences between predicted and measured.

The significantly higher $\Delta \mathrm{H}_{\mathrm{rx}}$ measured by the ARC relative to the DTA is expected because for gasproducing reactions. Gases carry heat away from the DTA's sensors before the heat can be seen. In contrast, the ARC is an adiabatic calorimeter with a sealed containment system with no loss of heat and is thus able to see all of the heat produced. Unfortunately, the ARC-measured $\Delta \mathrm{H}_{\mathrm{rx}}$ is significantly higher than predicted for the cellulose reaction with nitrate, and we have no explanation for the difference. 


\subsection{Gas Products}

The identities of the cellulose/nitrate reaction products are important for two reasons. First, introducing cellulose creates the potential for hydrogen production, which could introduce a flammability hazard. Second, the composition of the gases provides insight into the chemical reaction, which can be used to calculate the thermodynamics of the cellulose reaction with nitrate.

To determine if hydrogen is a major product, we analyzed the residual gases from the second ARC experiment using gas MS. As provided in Table 3.5, the residual gas contained $49.7 \mathrm{~mol} \%$ nitrogen, $44.4 \mathrm{~mol} \% \mathrm{CO}_{2}, 5 \mathrm{~mol} \% \mathrm{~N}_{2} \mathrm{O}$, hydrogen, and lower values of nitric oxide, methane, and the higher hydrocarbons. The relative $\mathrm{CO}_{2}: \mathrm{N}_{2}$ stoichiometry is near 0.9 , which argues for some production of $\mathrm{N}_{2} \mathrm{O}$.

This residual gas analysis shows that only very small amounts of hydrogen remain after heating the sample to $450^{\circ} \mathrm{C}$. If this residual gas is representative of the gases produced, these results would indicate that only small amounts of hydrogen are produced and are present at non-hazardous levels. Other flammable gases are present, but also at small concentrations; e.g., methane was the highest at $0.2 \mathrm{~mol} \%$. The pressure data in the third ARC run are low, presumably because of a leak. However, if the composition data are valid, then the pressure-release rates from the first ARC run (see Figure 3.10) should be applicable. The partial pressure of hydrogen released would be $1.2 \times 10^{-7} \mathrm{~mol} \mathrm{H}_{2} / \mathrm{min} / \mathrm{g}$ and that of methane, $4.5 \times 10^{-7} \mathrm{~mol} \mathrm{CH}_{4} / \mathrm{min} / \mathrm{g}$.

Table 3.5. Residual Gases from Second ARC Experiment as Measured by MS

\begin{tabular}{||c|c|c|c|}
\hline Gas & PP (torr) & mol\% & mass \% \\
\hline $\mathbf{H}_{2}$ & $1.5 \times 10^{-05}$ & 0.049 & 0.003 \\
\hline $\mathbf{C H}_{\mathbf{4}}$ & $5.5 \times 10^{-05}$ & 0.18 & 0.08 \\
\hline $\mathbf{N}_{\mathbf{2}}$ & $1.5 \times 10^{-02}$ & 49.76 & 38.76 \\
\hline $\mathbf{C}_{\mathbf{2}} \mathbf{H}_{\mathbf{y}}$ & $9 \times 10^{-06}$ & 0.030 & 0.025 \\
\hline $\mathbf{O}_{2}$ & $6 \times 10^{-06}$ & 0.020 & 0.018 \\
\hline $\mathbf{A r}$ & $9 \times 10^{-06}$ & 0.030 & 0.002 \\
\hline $\mathbf{C} \mathbf{O}_{\mathbf{2}}$ & $1.4 \times 10^{-02}$ & 44.38 & 54.32 \\
\hline $\mathbf{N}_{\mathbf{2}} \mathbf{O}$ & $1.7 \times 10^{-03}$ & 5.48 & 6.70 \\
\hline $\mathbf{C}_{\mathbf{x}} \mathbf{H}_{\mathbf{y}}$ & $2.2 \times 10^{-05}$ & 0.072 & 0.089 \\
\hline \hline
\end{tabular}

While the mass data are more sensitive than the infrared data, the two methods are complimentary with MS observing $\mathrm{N}_{2}$, a predicted major gas product. The water content is difficult to observe from the mass experiment because the spectrometer is a dry system, and water is removed from the sample on its path to the instrument. The $\mathrm{NO}_{\mathrm{x}}$ gases $\mathrm{N}_{2} \mathrm{O}$ and $\mathrm{NO}_{2}$ quite often are difficult to observe because they have mass fragments near that of $\mathrm{CO}_{2}$. Because the $\mathrm{CO}_{2}$ concentration is very large in these samples, it significantly overlaps the $\mathrm{NO}_{\mathrm{x}}$ signal. In the IR experiment, the frequencies of $\mathrm{NO}_{2}, \mathrm{~N}_{2} \mathrm{O}, \mathrm{NO}, \mathrm{CO}_{2}$, and water are well resolved from each other.

The IR analyses of the ARC experiments' residual gases indicated that when the reaction between cellulose and nitrate is allowed to go to completion, $\mathrm{CO}_{2}$ and water are formed or released as shown in Figure 3.14. Smith et al. (1999) predicted $\mathrm{N}_{2} \mathrm{O}$ formation also. It should be noted that the other expected product gas, $\mathrm{N}_{2}$, is not IR active and thus not visible in our IR analyses. Most testing with organic/nitrate reactions have indicated the presence of the nitrogen oxides (Smith et al. 1999) in the off-gases. We do 
not have an explanation for the absence of $\mathrm{N}_{2} \mathrm{O}$ unless the mechanism is not as Smith et al. postulated, or the $\mathrm{N}_{2} \mathrm{O}$ back reacts with cellulose after it has been produced.

The back-reaction possibility is supported by the IR analyses of the residual gas from the third ARC experiment presented in Figure 3.15. $\mathrm{N}_{2} \mathrm{O}$ is present in the spectrum along with water vapor and $\mathrm{CO}_{2}$. The inset argues that perhaps a bit of $\mathrm{NO}_{2}$ is formed as well, but the band is hidden under the water-vapor band. Since this is the largest intensity band, very little $\mathrm{NO}_{2}$ formed. Although we observed pungent organic odors when these residual ARC solids were recovered, the IR saw no organic gases that could be associated with these odors.

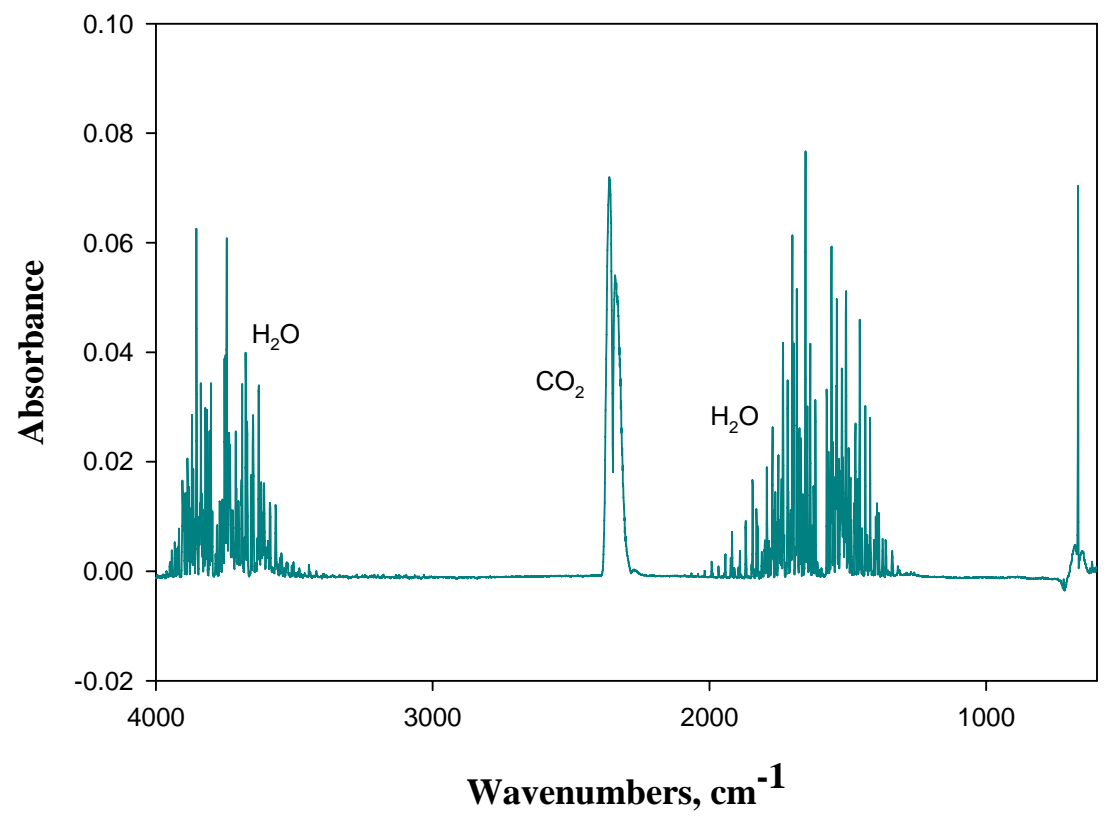

Figure 3.14. IR Spectrum of Residual Gases from Heating Simulated ES-31F Feed, ARC Experiment\#2

The residual gas analyses suggest that little flammable gas is produced or, more accurately, remains after heating to $450^{\circ} \mathrm{C}$. The observation of pungent organic odors after the large-scale ARC experiment suggest that organics form, but the IR found no IR-active organics in the residual gas, indicating that none formed even when the reaction was stopped at $225^{\circ} \mathrm{C}$. The observed gases support Smith et al.'s postulated reaction except for the significant absence of $\mathrm{N}_{2} \mathrm{O}$. The conclusion that little flammable gases were produced must be tempered by the possibility that the flammable and oxidizing gases may have reacted during the experiments.

\subsection{Reaction Kinetics}

Reaction kinetics are important for any required engineering analyses for assessing the heat-dissipation capabilities of the engineered system or what engineered hazard mitigations are required to make sure no uncontrolled propagating reaction occurs. 


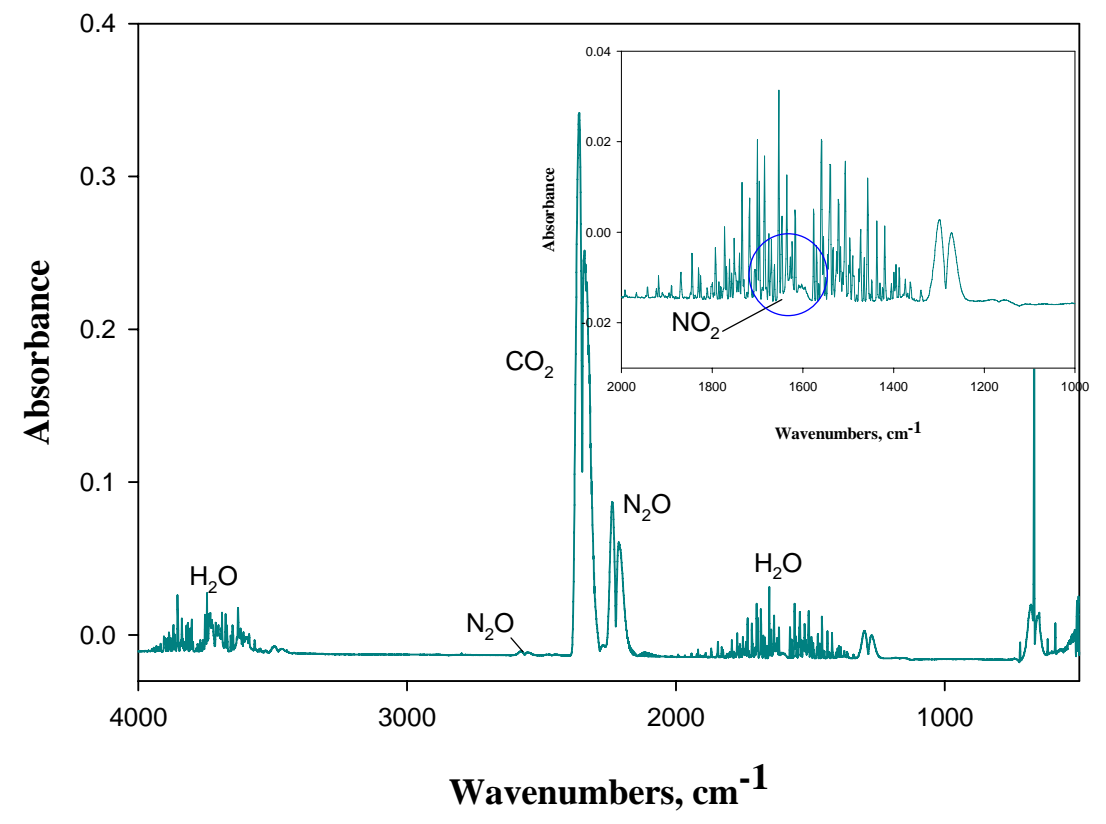

Figure 3.15. IR Spectrum of Residual Gases from Third ARC Analysis of ES-31F Simulated Feed

Using the DTA results and applying Kissinger's (1957) graphical method, see Figure 3.16, the measured Arrhenius kinetic parameters $\mathrm{E}_{\mathrm{a}}$ and $\mathrm{A}$ for the major gas-producing cellulose denitration reaction beginning near $290^{\circ} \mathrm{C}$ were $186 \mathrm{~kJ} /$ mole and $3 \times 10^{14} \mathrm{~s}^{-1}$, respectively or in terms of the Arrhenius rate constant $\mathrm{k}=3 \times 10^{14} \mathrm{~s}^{-1} \exp (-186 \mathrm{~kJ} / \mathrm{mole} / \mathrm{RT})$ where $\mathrm{R}$ is the gas constant and $\mathrm{T}$ is temperature. In Kissinger's (1957), Ozawa's (1965), and Flynn and Wall's (1966) graphical approaches, the slope of the least-squares regression is $-\mathrm{E}_{\mathrm{a}} / \mathrm{RT}$, and $\mathrm{A}$ is derived from the intercept.

Flynn and Wall's (1966) similar graphical method yields a similar $\mathrm{E}_{\mathrm{a}}$ of $186 \mathrm{~kJ} / \mathrm{mol}(44.4 \mathrm{kcal} / \mathrm{mol})$ that is in good agreement with the Kissinger method. The preexponential of $1.8 \times 10^{12} \mathrm{~s}^{-1}$ is a factor of 0.006 of that determined by the Kissinger method. Without further investigation, we do not have an explanation for the difference between the two preexponential or frequency factors. 


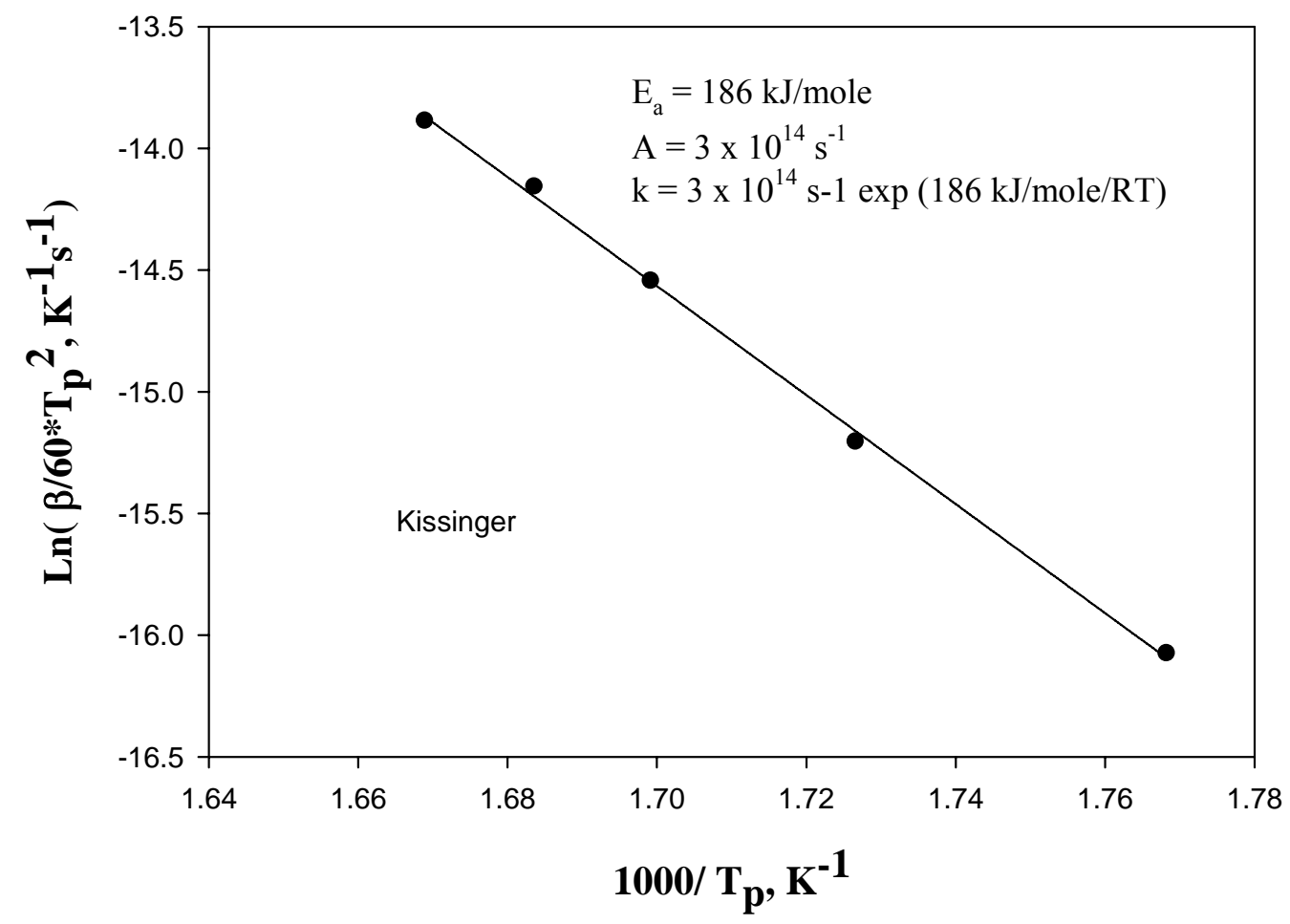

Figure 3.16. Plot of $\beta$ vs $1 / \mathrm{T}$ to Determine Arrhenius Kinetic Parameters (Kissinger 1957) 


\subsection{Conclusions}

PNNL's thermoanalytical studies of cellulose's reaction with nitrate and nitrite in the ES-31F simulated BV feed found that

- $\quad$ The reaction proceeds in three (possibly four) distinct steps, beginning at $110^{\circ} \mathrm{C}$ (ARC) and completing above $550^{\circ} \mathrm{C}$ (TG/DTA).

- The lower temperature reactions in the BV feed are distinct from those of cellulose's reaction with sodium nitrate, but above $280^{\circ} \mathrm{C}$, the reactions are similar.

- The principal product gases are those postulated by Smith et al. (1999).

- Based on analysis of the residual gases after an ARC experiment to $450^{\circ} \mathrm{C}$, only small amounts of the flammable gases hydrogen or methane remain, suggesting either limited flammable gas production or gas-phase reactions between the flammables and the oxidizing gases produced by the reaction between nitrate and cellulose.

- For 1- to 6-g quantities, the reaction onset temperature for $\mathrm{ES}-31 \mathrm{~F}$ feed is near $110^{\circ} \mathrm{C}$ under adiabatic and sealed conditions, which is less than the $50^{\circ} \mathrm{C}$ rule-of-thumb safety margin recommended by CCPS for reactive chemical systems with no engineered controls of the expected operational temperature of the dryer.

- Once initiated under adiabatic conditions, the cellulose nitrate reaction or series of reactions will continue until completed with significant gas release.

- Engineering analyses of actual process systems are required to determine if the reaction is capable of sustaining itself under non-adiabatic conditions. Although the DTA analyses suggest that when gases are rapidly exhausted from the chemical system, significant heat is removed. These DTA analyses are not representative of larger chemical systems where the product, heat-bearing gases have an opportunity to significantly interact with residual solids. Such evaluations would require an understanding of the chemical process, reaction rates, and thermal properties (e.g., thermal conductivity) under any particular set of process or process-upset conditions.

- Additional studies are needed to unconfound the chemistry of the nitrate/cellulose chemical system to better understand whether a reaction is due to the decomposition of cellulose or the binary reaction between the nitrate and cellulose or whether the observed reaction arises from the reaction of nitrate with the cellulose decomposition products. Such information permits a knowledgeable development of mitigating or accommodating strategies.

In summary, our studies indicate that the cellulose-treated LAW is a complex chemical system capable of supporting self-propagating reactions that are observable by the $\mathrm{ARC}$ near $100^{\circ} \mathrm{C}$. It is worth noting that in other larger scale $(22 \mathrm{~L})$ drying operations, no exothermic reactions were observed. The chemical mechanism and the products, including the gaseous products, are not well characterized. The cellulose/nitrate reaction is capable of supporting self-sustaining reactions beginning within $50^{\circ} \mathrm{C}$ (the CCPS-recommended safety margin) of the vacuum dryer operating temperature, $60^{\circ} \mathrm{C}$. Therefore, engineering evaluations are recommended to make sure that the engineered systems have the capability to mitigate heat and gas-production rates and that storage conditions and the time to prepare feed will preclude a propagating reaction. 


\subsection{References}

Antal Jr, MJ, Friedman, and FE Rogers. 1980. "Kinetics of Cellulose Pyrolysis in Nitrogen and Steam." Comb. Sci. Tech. 21(3, 4):141.

Bagaasen LM, TM Brouns, ML Elliott, PR Hrma, D-S Kim, J Matyáš, EM Pierce, BP Mcgrail, MJ Schweiger, AE Beck, and BE Campbell. 2006. In: Transport of Technetium and Rhenium into Refractory Materials during Bulk Vitrification. WM'06, Waste Management Symposium, February 26March 2, 2006, Tucson, Arizona.

Barin I. 1989. Thermochemical Data of Pure Substances. VCH, New York.

Beitel GA. 1976a. Chemical Stability of Salt Cake in the Presence of Organic Materials. ARH-LD-119, Atlantic Richfield Hanford Company, Richland, Washington.

Beitel GA. 1976b. Sodium Nitrate Combustion Limit Tests. ARH-LD-123, Atlantic Richfield Hanford Company, Richland, Washington.

Beitel GA. 1976c. Final Report on Investigation of Stability of Organic Material in Salt Cake. ARHLD-126, Atlantic Richfield Hanford Company, Richland, Washington.

Beitel GA. 1977. Exothermic Potential of Sodium Nitrate Salt Cake, ARH-LD-163, Atlantic Richfield Hanford Company, Richland Washington.

Davies D, AR Horrocks, and M Greenhalgh. 1983. "Ignition Studies on Cotton Cellulose by DTA." Thermochimica Acta 63(1983):351-362.

Dollimore D, and JM Hoath. 1981. "The Application of Thermal Analysis to the Combustion of Cellulose.” Thermochimica Acta 45(1981):87-102.

Flynn JH, and LA Wall. 1966. "General Treatment of Thermogravimetry of Polymers.” J. Res. Nat. Bur. Std, Section A-Physics And Chemistry, A 70(6):487.

Heemskerk, AH, AC Hordijk, AT Lanning, JC Lont, H Schell, and P Schuurman. 1995. Guidelines for Chemical Reactivity Evaluation and Application to Process Design. Center for Chemical Process Safety of the American Institute of Chemical Engineers, New York.

Hrma PR, LM Bagaasen, AE Beck, TM Brouns, DD Caldwell, ML Elliott, J Matyas, KBC Minister, MJ Schweiger, DM Strachan, BP Tinsley, and GW Hollenberg. 2005. Bulk Vitrification Castable Refractory Block Protection Study. PNNL-15193, Pacific Northwest National Laboratory, Richland, Washington.

Hrma PR, LM Bagaasen, MJ Schweiger, MB Evans, BT Smith, BM Arrigoni, D-S Kim, CP Rodriguez, ST Yokuda, J Matyáš, WC Buchmiller, AB Gallegos, and A Fluegel. 2007. Bulk Vitrification Performance Enhancement: Refractory Lining Protection Against Molten Salt Penetration. PNNL-16773, Pacific Northwest National Laboratory, Richland, Washington. 
Kim DS, CZ Soderquist, JP Icenhower, BP McGrail, RD Scheele, BK McNamara, LM Bagaasen, MJ Schweiger, JV Crum, JD Yeager, J. Matyáš, LP Darnell, HT Schaef, AT Owen, AE Kozeliskey, LA Snow, and MJ Steele. 2005. Tc Reductant Chemistry and Crucible Melting Studies with Simulated Hanford Low-Activity Waste. PNNL-15131, Pacific Northwest National Laboratory, Richland, Washington.

Kissinger HE. 1957. "Reaction Kinetics in Differential Thermal Analysis.” Anal. Chem. 1702:29.

Madorsky, SL, VE Hart, and S Straus. 1956. "Pyrolysis of Cellulose in a Vacuum." J. Res. Nat. Bur. Stand 56:343.

Milosavljevic I, and EM Suuberg. 1995. "Cellulose Thermal Decomposition Kinetics: Global Mass Loss Kinetics.” Ind. Eng. Chem. Res. 34:1081.

Milosavljevic, I, V Oja, and EM Suuberg. 1996. "Thermal Effects in Cellulose Pyrolysis: Relationship to Char Formation Processes." Ind. Eng. Chem. Res. 35:653.

Ozawa T. 1965. "A new Method of Analyzing Thermogravimetric Data." Bulletin of the Chemical Society of Japan 38(11):1881-1886.

Raemy A, and TF Schweizer. 1983. "Thermal Behavior of Carbohydrates Studied by Heat Flow Calorimetry.” J. Thermal Analysis 28:95-108.

Raemy A, and M Ottaway. 1991. "The Use of High Pressure DTA, Heat Flow, and Adiabatic Calorimetry to Study Exothermic Reactions." J. Thermal Analysis 37:1965-1971.

Scheele RD, JL Sobolik, RL Sell, and LL Burger. 1995. Organic Tank Safety Project: Preliminary Results of Energetics and Thermal Behavior Studies of Model Organic Nitrate and/or Nitrite Mixtures and a Simulated Organic Waste. PNL-10213, Pacific Northwest National Laboratory, Richland, Washington.

Scheele RD, TD Cooper, SA Jones, JR Ewalt, JA Compton, DS Trent, MK Edwards, AE Kozelisky, PA Scott, and MJ Minette. 2005. Thermal Stability Studies of Candidate Decontamination Agents for Hanford's Plutonium Finishing Plant Plutonium-Contaminated Gloveboxes. PNNL-15410, Pacific Northwest National Laboratory, Richland, Washington.

Shimskey RW, WC Buchmiller, and MR Elmore. 2007. Littleford-Day Dryer Operation- Dryer Operation Impacts of Proposed MIS Mitigation Changes. PNNL-16659, Pacific Northwest National Laboratory, Richland, Washington.

Shoemaker DP, CW Garland, and JW Nibler. 1996. Experiments in Physical Chemistry. McGraw-Hill, New York.

Smith HD, EO Jones, AJ Schmidt, AH Zacher, MD Brown, MR Elmore, and SR Gano. 1999. Denitration of High Nitrate Salts Using Reductants. PNNL-12144, Pacific Northwest National Laboratory, Richland, Washington.

Townsend DI, and JC Tou. 1980. "Thermal Hazard Evaluation by an Accelerating Rate Calorimeter." Thermochimica Acta 37:1-30. 
Várhegyi G, P Szabó, W S-L Mok, and MJ Antal, Jr. 1993. "Kinetics of the thermal decomposition of cellulose in sealed vessels at elevated pressures. Effects of the presence of water on the reaction mechanism." J. Anal. Appl. Pyrolysis, 26 (19993) 159-174.

Wahl KL, JA Campbell, SA Clauss, BD Lerner, AK Sharma, AJ Saenz, IE Burgeson, RL Sell, KE Grant, GM Mong, CE Petersen, SA Bryan, and RD Scheele. 1995. Advanced Organic Analysis and Analytical Methods Development: FY 1995 Progress Report. PNL-10777, Pacific Northwest Laboratory, Richland, Washington.

Witwer KS, ES Dysland, and D-S Kim. 2007. Demonstration Bulk Vitrification System (DBVS) Series 38 Full-Scale Testing, 38C Test Report. 34006-RT-0003, Rev. 0, AMEC Earth \& Environmental, Inc, Richland, WA.

Wu KT, and E Zavarin. 1984. "Thermal Analysis of Mixtures of Nitrates and Lignocellulosic Materials." Thermochimica Acta 107:131-148. 


\section{Distribution}

No. of

Copies

OFFSITE

2 AMEC

K. S. Witwer

B2-67

B. Campbell

B2-67

\section{ONSITE}

8 CH2M HILL, Inc.

P.K. Brockman

H6-03

F.R. Miera

R.E. Raymond

D. Shuford

J.P. Harris

J.E. Van Beek (3)
No. of

Copies

\section{ONSITE}

15 Pacific Northwest National Laboratory

L. M. Bagaasen (5) K6-28

P.K. Berry P7-22

S.J. Bos P7-22

T. M. Brouns K9-69

M. L. Elliott K6-28

A.E. Kozelisky P7-25

J. Matyas K6-24

B.K. McNamara P7-25

R.D. Scheele (2) P7-25

M. J. Schweiger K6-24

3 U.S. Department of Energy/Office of River

Protection

B. J. Harp

H6-60

D. H. Irby

H6-60

B. M. Mauss

H6-60

Distr. 1 